\title{
Heliox administration in anesthetized rabbits with spontaneous inspiratory flow limitation
}

\footnotetext{
Edgardo d'Angelo ${ }^{1}$, Matteo Pecchiari ${ }^{1}$, François Bellemare ${ }^{1}$, Gabriele Cevenini ${ }^{2}$, and Paolo Barbini $^{3}$
}

${ }^{1}$ Department of Physiopathology and Transplantations, Università di Milano, Milan, Italy, ${ }^{2}$ Department of Medical Biotechnologies, Università di Siena, Siena, Italy, ${ }^{3}$ Department of Information Engineering and Mathematics, Università di Siena, Siena, Italy.

RUNNING TITLE: Heliox and inspiratory flow limitation

DOI: 10.1152/japplphysiol.00830.2020

*Corresponding author: Matteo Pecchiari, Università degli Studi di Milano, Dipartimento di Fisiopatologia e dei Trapianti, via Mangiagalli 32, 20133 Milan, Italy

E-mail address: matteo.pecchiari@unimi.it 


\begin{abstract}
We investigated the effects of heliox administration $\left(80 \%\right.$ Helium in $\left.\mathrm{O}_{2}\right)$ on tidal inspiratory flow limitation (tIFL) occurring in supine anesthetized spontaneously breathing rabbits, regarded as an animal model of obstructive apnea-hypopnea syndrome. 22 rabbits were instrumented to record oronasal mask flow, airway opening, tracheal and esophageal pressures and diaphragm and genioglossus electromyographic activities while breathing either room air or heliox, and, in 12 rabbits, also during the application of continuous positive airway pressure (CPAP; $6 \mathrm{cmH} 2 \mathrm{O}$ ). For the group, heliox increased peak inspiratory flow, ventilation (18 $\pm 11 \%)$, peak inspiratory tracheal and dynamic transpulmonary pressures, but in no animal eliminated tIFL, as instead CPAP did in all. Muscle activities were unaffected by heliox. In the presence of IFL the increase in flow with heliox $(\Delta \dot{\mathrm{V}} \mathrm{IFL})$ varied markedly among rabbits (2 to $49 \%$ ), allowing the distinction between responders and non-responders. None of the baseline variables discriminated responders and nonresponders. However, fitting the Rohrer equation $\left(\mathrm{R}=\mathrm{K}_{1}+\mathrm{K}_{2} \dot{\mathrm{V}}\right)$ to the tracheal pressure-flow relationship over the first $0.1 \mathrm{~s}$ of inspiration while breathing air allowed such discrimination on the basis of larger $\mathrm{K}_{2}$ in responders $\left(0.005 \pm .002 \mathrm{vs} 0.002 \pm .001 \mathrm{cmH}_{2} \mathrm{O} \cdot \mathrm{s}^{2} \cdot \mathrm{ml}^{-2} ; \mathrm{p}<0.001\right)$, suggesting a corresponding difference in the relative contribution of laminar and turbulent flow. The differences in $\Delta \dot{V}$ IFL between responders and non-responders were simulated by modeling the collapsible segment of the upper airways as a non-linear resistor and varying its pressure-volume curve, length and diameter, thus showing the importance of mechanical and geometrical factors in determining the response to heliox in the presence of tIFL.
\end{abstract}

NEW \& NOTEWORTHY In an obstructive sleep apnea rabbit model, heliox never abolishes tidal inspiratory flow limitation (IFL), but increases inspiratory flow and tidal volume, substantially in some and nearly nil in other animals. Positive response to heliox cannot be predicted on the basis of breathing pattern characteristics or upper airway resistance that preceded IFL onset, but is related to the mechanical and geometrical features of upper airway collapsible segment, as indicated by model simulation.

Key words: heliox; inspiratory flow limitation; obstructive sleep apnea and hypopnea; rabbit; upper airways 


\section{INTRODUCTION}

Obstructive sleep apneas and hypopneas $(\mathrm{OSAH})$ are characterized by recurrent episodes of complete or partial obstruction of extrathoracic airways with reduced ventilation and progressive arterial hypoxemia and hypercapnia, that are usually terminated by brief arousals (1). Although this condition can be effectively treated by means of continuous positive airway pressure (CPAP) applied via a nasal mask (35), this form of treatment is not without side effects and is often poorly tolerated. Strong evidence exists that in most OSAH patients the obstruction occurs at the level of the oropharynx due to a reduction of tonic and phasic activity of dilating muscles $(9,32)$, and in fact direct hypoglossus nerve stimulation can reverse upper airway obstruction in OSAH patients (13). However, a clinical trial (33) has revealed a number of problems with hypoglossus nerve stimulation in a majority of patients, the related discomfort still representing an important limitation, in spite of the more recent technical improvements brought to this therapeutic treatment (39).

Administration of helium-oxygen mixtures (heliox) has been proposed as early as 1934 by Barach (2) to relieve dyspnea in patients with severe asthma, and several, more recent studies have explored the potential of heliox administration in severe COPD patients (cfr. 31). However, beneficial effects of heliox in both asthmatic and COPD patients at rest have been reported only sporadically, and the majority of the studies performed until now suggests that heliox is not a primary therapeutic option for these disease entities $(22,31)$. On the other hand, given the physical properties of heliox, the justification for its use seems to be the most compelling in patients with upper airway obstruction, considering that in this respiratory tract turbulence develops even during normal, quiet breathing. Yet, there are few studies that support the efficacy of heliox administration in this setting $(10,18,22,38)$, and none in OSAH patients.

The presence of inspiratory flow limitation during tidal breathing (tIFL) should realize a condition very close to OSAH, and an animal model that mimics the essential features of OSAH could be useful in assessing the therapeutic potential of heliox administration. It has been shown in fact that IIFL can occur in spontaneously breathing, anesthetized, supine rabbits, and that IFL can be reversed by hypoglossus nerve stimulation, besides continuous positive pressure breathing (5). Here, we have used this animal model to gain information about the effectiveness of heliox administration in dealing with tIFL, also in view of its possible use in patients.

\section{METHODS}

All surgical and experimental procedures were carried in accordance with the principles and guidelines of the European Community for the use and care of experimental animals. Twenty-two New Zealand White rabbits (body weight: $2.4-3.0 \mathrm{~kg}$ ) were anesthetized with propofol $\left(5 \mathrm{mg} \cdot \mathrm{kg}^{-1}\right)$ 
and urethane $\left(1 \mathrm{~g} \cdot \mathrm{kg}^{-1}\right)$. Adequate levels of anesthesia, judged from the absence of nociceptive and withdrawal reflexes, were ensured by additional doses of anesthetics. At the end of the experiments the animals were euthanized with an overdose of anesthetics. A mouth-occluding mask was held in place with rubber bands and sealed with silicone grease. Airflow $(\dot{V})$ through the mask was measured with a pneumotachograph (Fleish n ${ }^{0}$ 00, HS Electronics, March-Hugstetten, Germany) and differential pressure transducer (Statham 270, Hewlett Packard, Palo Alto, CA). The pneumotachograph was calibrated using a syringe filled with air or heliox. Airway opening, tracheal and esophageal pressures were measured with pressure transducers (Model 1290A, Hewlett Packard) connected to a side port of the mask, a balloon-tipped catheter, and a side arm of the tracheal cannula, respectively. The esophageal catheter was inserted via a lateral approach low in the neck, and tied to both extremes of the esophageal incision. Adequacy of the esophageal signal was checked using the occlusion method (4), and its consistency further ensured by the constancy, throughout the experiment, of the dynamic lung elastance during air and heliox breathing at ambient pressure. The metal cannula $(2.2 \mathrm{~cm}$ long, $0.45 \mathrm{~cm}$ ID) with a side arm $(0.35 \mathrm{~cm}$ OD) was inserted through a $\sim 1 \mathrm{~cm}$ incision made in the ventral aspect of the trachea, initiated a 3-4 rings below the larynx, and tightly bounded to the trachea by means of ligatures. The ratio of trachea-to-cannula internal diameter was always such to render the Bernoulli effect immaterial. The bared 2-3 mm of three pairs of fine, teflon coated wires were inserted into the right and left genioglossus muscles and the diaphragm through the sternal apophysis, and connected to a custom-build apparatus that amplified, rectified and integrated (time constant $=0.1 \mathrm{~s})$ the electromyographic (EMG) activity. All signals were sampled at $200 \mathrm{~Hz}$ by a 12 -bit A/D converter (AT MIO16E-10, National Instruments, Austin, Tx) and stored on computer. Volume changes were obtained by numerical integration of the flow signal.

Procedures. Animals were studied while breathing spontaneously in the supine posture. All exhibited tIFL while breathing air at ambient pressure, flow-limitation consisting in invariance or decrease of airflow paralleled by an increasing driving pressure. Tests consisted of a 10-12 min period of air breathing $(\mathrm{AB})$ followed by a similar period of heliox ( $80 \% \mathrm{He}$ in oxygen) breathing (HB). In 22 animals tests were repeated three times while breathing at zero end-expiratory pressure (ZEEP). In 12 rabbits tests were also performed during continuous positive pressure breathing; a CPAP of $6.1 \pm 0.2 \mathrm{~cm} \mathrm{H}_{2} \mathrm{O}$ was applied by means of a flow-through system connected to the pneumotachograph.

To check whether the insertion of the tracheal cannula and muscle electrodes might have caused any effect, in 7 rabbits mask flow and esophageal pressure were measured before and after 
the insertion of those devices, but no appreciable differences were noted in the breathing pattern, tIFL, and response to HB between the two conditions.

Data analysis. For each animal and condition, 15-30 breaths were analyzed while breathing air and heliox, respectively, using a house-made program running on Labview (National Instruments, Austin, TX). After having assessed from the flow tracing the inspiratory (TI) and expiratory duration (TE), each phase was normalized with respect to its duration. The signals of each normalized breath consisted of 200 inspiratory and expiratory values, respectively, plus 40 values that covered the period preceding the onset of inspiration. These normalized breaths were then averaged and the time axis recreated using the corresponding mean TI and TE. Owing to the presence in the inspiratory flow and tracheal pressure tracings of occasionally substantial oscillations, these were smoothed with a 3-5 points moving average. Each condition was therefore represented by a single average breath for air and heliox breathing, respectively. Figure 1 shows flow, volume, and pressure records obtained with the above procedure in an intact rabbit breathing ambient air on ZEEP.

From the normalized, average breath, the following parameters were automatically obtained: tidal volume (VT), breathing frequency (f), pulmonary ventilation ( $\dot{\mathrm{V} E}$ ), airway opening pressure (Pao), dynamic lung elastance (Edyn), peak inspiratory and expiratory flow (ن்,pk and VE,pk), tracheal (Ptr,I,pk and Ptr,E,pk), and dynamic transpulmonary pressure (Pdyn,I,pk and Pdyn,E,pk), and peak diaphragmatic and genioglossal EMG activity (Adi,pk and Agg,pk). Pdyn was computed using the elastic subtraction method $(22,35)$, as indicated in Figure 1.

Onset (t,on), and duration $(\Delta t)$ of IFL were assessed from the flow tracing and the $\dot{V}$-Ptr and $\dot{\mathrm{V}}$-Pdyn diagrams, as shown in Figure 1. IFL was characterized by the following parameters: mean

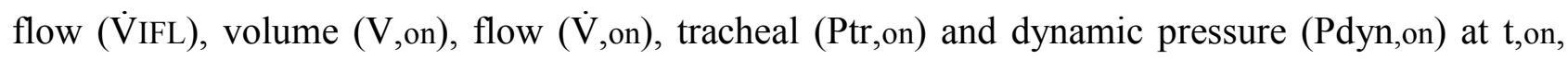
and amount of VT involved $(\Delta \mathrm{V})$.

Given the looping of the pressure-flow curves, upper airway (Rua) and pulmonary resistance (RL) were computed for each animal and condition as the mean of the instantaneous (Ptr-Pao) $/ \dot{V}$ and $\mathrm{Pdyn} / \dot{\mathrm{V}}$ ratios recorded during the inspiratory or expiratory phase, thus providing the average resistance of the given period. However, in the presence of IFL, the inspiratory resistance was computed using only data obtained before the onset of IFL. Lower airway and lung tissue resistance (Rla) was obtained as RL-Rua; however, Rla was taken as a measure of lower airway resistance, lung tissue resistance being independent of air or heliox breathing, besides lung volumes in the range observed herein $(13,14)$. Finally, in a group of rabbits, selected on the basis of their very different response to heliox administration, $-\mathrm{Ptr}-\dot{\mathrm{V}}$ and $-\mathrm{Pdyn}-\dot{\mathrm{V}}$ data pertaining to the initial $0.1 \mathrm{~s}$ of inspiration during air breathing on ZEEP were fitted to Rohrer equation $\mathrm{R}=\mathrm{K}_{1}+\mathrm{K}_{2} \cdot \dot{\mathrm{V}}$. 
Statistics. Analyses were performed using SPSS 11.5 (SPSS Inc., Chicago, IL). Data are presented as mean $\pm \mathrm{SD}$, unless stated otherwise. Comparisons among conditions were performed using the repeated measurements ANOVA or the Student t-test for paired and unpaired measures, as needed. Regression analysis was performed using the least square method. The level for statistical significance was taken at $\mathrm{p} \leq 0.05$.

\section{GLOSSARY}

\begin{tabular}{|c|c|c|}
\hline VT & $\mathrm{ml}$ & tidal volume \\
\hline TI & s & duration of inspiration \\
\hline TE & $\mathrm{s}$ & duration of expiration \\
\hline $\mathrm{f}$ & $\min ^{-1}$ & breathing frequency \\
\hline$\dot{\mathrm{V}} \mathrm{E}$ & $\mathrm{ml} \cdot \mathrm{min}^{-1}$ & pulmonary ventilation \\
\hline$\dot{\mathrm{V}} \mathrm{I}, \mathrm{pk}$ & $\mathrm{ml} \cdot \mathrm{s}^{-1}$ & peak inspiratory flow \\
\hline Ptr,I, pk & $\mathrm{cmH}_{2} \mathrm{O}$ & peak inspiratory tracheal pressure \\
\hline Pdyn,I, pk & $\mathrm{cmH}_{2} \mathrm{O}$ & peak inspiratory dynamic transpulmonary pressure \\
\hline Edyn & $\mathrm{cmH}_{2} \mathrm{O} \cdot \mathrm{ml}^{-1}$ & dynamic lung elastance \\
\hline$\dot{\mathrm{V}} \mathrm{E}, \mathrm{pk}$ & $\mathrm{ml} \cdot \mathrm{s}^{-1}$ & peak expiratory flow \\
\hline Ptr,E, pk & $\mathrm{cmH}_{2} \mathrm{O}$ & peak expiratory tracheal pressure \\
\hline Pdyn,E, pk & $\mathrm{cmH}_{2} \mathrm{O}$ & peak expiratory dynamic transpulmonary pressure \\
\hline Adi, pk & arbitrary units & integrated diaphragmatic electrical activity \\
\hline Agg, pk & arbitrary units & integrated genioglossal electrical activity \\
\hline IFL & & inspiratory flow limitation \\
\hline$\dot{\text { VIFL }}$ & $\mathrm{ml} \cdot \mathrm{s}^{-1}$ & mean flow during IFL \\
\hline t,on & $\mathrm{S}$ & time of IFL onset \\
\hline$\Delta \mathrm{t}$ & S & duration of IFL \\
\hline V,on & $\mathrm{ml}$ & inspired volume at IFL onset \\
\hline$\Delta \mathrm{V}$ & $\mathrm{ml}$ & amount of VT exhibiting IFL \\
\hline$\dot{\mathrm{V}}$,on & $\mathrm{ml} \cdot \mathrm{s}^{-1}$ & flow at IFL onset \\
\hline Ptr,on & $\mathrm{cmH}_{2} \mathrm{O}$ & tracheal pressure at IFL onset \\
\hline Pdyn,on & $\mathrm{cmH}_{2} \mathrm{O}$ & dynamic transpulmonary pressure at IFL onset \\
\hline Adi,on & arbitrary units & integrated diaphragmatic activity at IFL \\
\hline Agg,on & arbitrary units & integrated genioglossal activity at IFL \\
\hline Rua & $\mathrm{cmH}_{2} \mathrm{O} \cdot \mathrm{s} \cdot \mathrm{ml}^{-1}$ & upper airway resistance \\
\hline $\mathrm{RL}_{\mathrm{L}}$ & $\mathrm{cmH}_{2} \mathrm{O} \cdot \mathrm{s} \cdot \mathrm{ml}^{-1}$ & pulmonary resistance \\
\hline Rla & $\mathrm{cmH}_{2} \mathrm{O} \cdot \mathrm{s} \cdot \mathrm{ml}^{-1}$ & lower airway and lung tissue resistance \\
\hline $\mathrm{K}_{1}$ & $\mathrm{cmH}_{2} \mathrm{O} \cdot \mathrm{s} \cdot \mathrm{ml}^{-1}$ & coefficient of Rohrer equation \\
\hline $\mathrm{K}_{2}$ & $\mathrm{cmH}_{2} \mathrm{O} \cdot \mathrm{s}^{2} \cdot \mathrm{ml}^{-2}$ & coefficient of Rohrer equation \\
\hline $\mathrm{h}_{1}$ & dimensionless & coefficient of Lambert equation \\
\hline $\mathrm{h}_{2}$ & dimensionless & coefficient of Lambert equation \\
\hline$\mu$ & poise & viscosity \\
\hline$\rho$ & $\mathrm{g} \cdot \mathrm{ml}^{-1}$ & density \\
\hline
\end{tabular}




\section{RESULTS}

Effect of heliox breathing during ventilation on ZEEP. The characteristics of IFL while breathing air or heliox at ambient pressure (ZEEP) are shown in Table 1. During air breathing, IFL initiated at $34 \pm 8 \%$ TI, and involved $57 \pm 12$ and $61 \pm 13 \%$ of TI and VT, respectively. VIFL was slightly but significantly lower than $\dot{\mathrm{V}}$, pk $(1.4 \pm 1.3 \mathrm{ml} / \mathrm{s} ; \mathrm{p}<0.001)$, reflecting the fact that in most animals peak inspiratory flow was reached before the onset of IFL (Figure 1). Interestingly, the pattern of genioglossus activity was ramp-like, similar to that of the diaphragm (Figure 2).

Relative to air breathing, VT, $\dot{V}$ E, $\dot{V}$ I,pk. $\dot{V}$ IFL and $\dot{\mathrm{V}}$,on increased while breathing heliox, whereas TI and VE,pk, decreased (Table 1). The relative increase of VंIFL and VE amounted to $17 \pm 14$ and $15 \pm 18 \%$, whereas that of VT was somewhat less $(12 \pm 13 \%)$, owing to shortening of TI. There was also a modest, but significant, increase of peak Ptr,I and Pdyn,I. All other parameters, including diaphragm and genioglossus muscle activity, remained unchanged.

The effects of heliox differed markedly among animals (Figure 2). Two groups, each of 8 rabbits, were identified, one exhibiting a strong response to heliox, the other the least, and conventionally defined as Responder and Non-responder (Table 2). In the former group (Responders), VT, VE, and VIFL increased by $26 \pm 10 \%, 38 \pm 12 \%$, and $34 \pm 9 \%$, respectively, whereas in the latter group (Non-responders), the increase was $4 \pm 5,5 \pm 4$, and $5 \pm 2 \%$, respectively. Though significantly increased in Non-responders, the changes of $\dot{V} E$, $\dot{V} I F L$ and $\dot{V}$,on were markedly smaller than those observed in Responders. Peak Ptr,I and Pdyn,I were increased in the latter, but unchanged in the former group. In Responders, both TI and TE shortened, the former significantly, and breathing frequency was significantly increased, thus concurring to the increase of VE. No change in breath timing occurred in Non-responders. In spite of the markedly different response to heliox breathing, during air breathing all parameters, including IFL characteristics, were similar for the two groups.

Effects of heliox breathing during CPAP ventilation. In the twelve animals eventually subjected to CPAP, the response to heliox breathing on ZEEP was comparable to that reported for all animals in Table 1, except for the increase of Peak Ptr,I and Pdyn,I which was irrelevant. As expected, continuous positive pressure (CPAP) increased TE substantially and decreased TI significantly, resulting in a fall of both $\mathrm{f}$ and $\dot{\mathrm{V}} \mathrm{E}$, in spite of an unchanged VT (Table 3). There was in fact a significant increase of diaphragmatic activity, which compensated for the concomitant increase in lung Edyn, likely a reflection of the elevated end-expiratory volume. In contrast, genioglossus muscle activity was significantly decreased, in line with the elevated mean airway pressure. Interestingly, the pattern of the inspiratory flow and genioglossus muscle activity became similar to 
that of anesthetized, tracheotomized rabbits breathing spontaneously at ambient pressure, i.e. a peak reached early in inspiration followed by a more or less rapid decline (Figure 2).

In all animals, CPAP eliminated tIFL, thus producing a marked increase of Pdyn,I,pk and $\dot{V} I$,pk, while the decrease of $\dot{V}$ E,pk occurred without significant changes of Pdyn,E,pk (Table 3). As expected because of the applied positive pressure, both Ptr,I,pk and Ptr,E,pk were increased, but the peak-to-peak difference of Ptr was markedly lower with CPAP $\left(10.8 \pm 2.9\right.$ vs $16.2 \pm 2.9 \mathrm{cmH}_{2} \mathrm{O}$; $\mathrm{p}<0.001$ ). Administration of heliox had no effects on any of these variables.

On removal of CPAP, all parameters returned to control values, and tIFL thus reappeared with unchanged characteristics (Table 3).

Upper and lower airway resistance. Examples of $\dot{\mathrm{V}}-\mathrm{Ptr}$ and $\dot{\mathrm{V}}-\mathrm{Pdyn}$ relationships from which inspiratory and expiratory RL and Rua, were obtained, are shown in Figure 1 and 3. As mentioned in Methods, inspiratory resistance in the presence of tIFL was computed over that part of the inspiratory Ptr- $\dot{\mathrm{V}}$ and Pdyn $-\dot{\mathrm{V}}$ relationship which preceded the onset of IFL.

While breathing on ZEEP, heliox caused a small but significant fall of RL and Rua both in inspiration (-10.4 $\pm 18.7 \%$ and $-8.2 \pm 17.2 \%$, respectively) and expiration $(-8.7 \pm 13.9 \%$ and $5.4 \pm 11.8 \%$, respectively), a greater fall occurring in Responders (Table 4). In contrast, no change in both RL and Rua took place with heliox in Non-responders. However, during air breathing both inspiratory and expiratory resistances did not differ significantly between Responders and Nonresponders. Whatever the effects of heliox on RL and Rua, Rla was essentially the same under all circumstances (Table 4).

In all animals on ZEEP, Rua did not differ significantly between expiration and inspiration during both air $\left(\Delta \mathrm{Rua}=0.001 \pm 0.031 \quad \mathrm{cmH}_{2} \mathrm{O} \cdot \mathrm{s} \cdot \mathrm{ml}^{-1} ; \quad \mathrm{P}=0.861\right)$ and heliox breathing $\left(\Delta \mathrm{Rua}=0.003 \pm 0.021 \mathrm{cmH}_{2} \mathrm{O} \cdot \mathrm{s} \cdot \mathrm{ml}^{-1} ; \mathrm{P}=0.521\right)$. In contrast, Rla was significantly higher in expiration during both air $\left(\Delta \mathrm{Rla}=0.008 \pm 0.014 \mathrm{cmH}_{2} \mathrm{O} \cdot \mathrm{s} \cdot \mathrm{ml}^{-1} ; \mathrm{P}=0.018\right)$ and heliox breathing $\left(\Delta \mathrm{Rla}=0.009 \pm 0.018 \mathrm{cmH}_{2} \mathrm{O} \cdot \mathrm{s} \cdot \mathrm{ml}^{-1}, \quad \mathrm{P}=0.032\right)$. The same applied to Responders and Nonresponders, in which, however, the difference was not significant, probably because of the smaller number of data.

The effect of heliox on both RL and Rua observed on ZEEP in the animals eventually subjected to CPAP (Table 5) were similar to those reported for all rabbits (Table 4), except for the decrease of expiratory RL and Rua which did not reach statistical significance, likely because of the smaller number of animals. Breathing air on CPAP decreased both inspiratory and expiratory RL and Rau significantly and by essentially the same amount, thus leaving Rla unchanged (Table 5). Heliox caused a further, though not significant, fall of both inspiratory and expiratory Rau, with no 
effect on Rla. On resumption of ventilation on ZEEP, all parameters resumed the pre-CPAP values (Table 5).

The mean values of the constants of Rohrer equation fitted to the $-\mathrm{Ptr}-\dot{\mathrm{V}}$ and $-\mathrm{Pdyn}-\dot{\mathrm{V}}$ data collected during the first $0.1 \mathrm{~s}$ of inspiration while breathing air on ZEEP are shown in Table 6, together with the average values of Rau and RL pertaining to the same period, separately for animals with (Responders) or without a positive response to heliox administration (Nonresponders). The mean values of $\mathrm{K}_{2}$ were significantly larger in Responders than in Nonresponders, whereas those of $\mathrm{K}_{1}$ were larger, though not significantly, in Non-responders than in Responders, for both upper airway and pulmonary $\mathrm{P}-\dot{\mathrm{V}}$ relation. The average values of Rau and $\mathrm{RL}$ did not differ, however, between the two groups of rabbits, as it was the case for the corresponding values computed over the entire period preceding the onset of IFL (Table 4).

\section{DISCUSSION}

The study has shown that in this animal model heliox administration, though unable to eliminate tIFL, positively affects pulmonary ventilation to a functionally relevant extent. Evaluated in terms of VIFL and VT augmentation, the response to heliox was highly variable among animals, ranging from nearly nil to 46 and 39\%, respectively. Nevertheless the average increase of both these parameters was significant, amounting to $17 \pm 14$ and $12 \pm 13 \%$, respectively (Table 1). Heliox administration had trivial effect on breath timing and no significant effect on breathing frequency (Table 1); the increase of $\dot{V} E$, which averaged $15 \pm 18 \%$, was thus due to that of VT. Such an increase, which in a normal lung at fixed breathing frequency and dead space should enhance alveolar ventilation by $\sim 20 \%$ and cause a corresponding fall in alveolar and arterial pCO2, would be effective in eliminating or substantially lessening the risk of compromising conditions. In those animals in which the increase of VIFL and VT was prominent both TI and TE shortened, because of the Hering-Breuer reflex and the centrally determined TI-TE linkage $(8,11,12)$; the breathing frequency increased significantly (Table 2), thus concurring to the more pronounced elevation of $\dot{V} E$ relative to that observed in the whole group of animals (Table 1) and especially in the Nonresponder group (Table 2).

None among the many parameters measured during air breathing (Table 1 and 4) could be used as a predictor of the ability of heliox to improve VIFL, VT, and $\dot{V}$, thus lessening the adverse effects of tIFL. Indeed, during air breathing similar breathing patterns, IFL characteristics, and airway resistances occurred in animals with prominent or quasi absent response to heliox administration (Table 2 and 5). No correlation could be found between the changes of $\dot{V}$ I,pk or VIFL with heliox and the average upper airway resistance measured before the onset of IFL during air 
breathing (Figure 4), although the marked inter-individual differences of the latter parameter might have been suggestive of a widely different presence of turbulence among animals and hence of the effects of heliox breathing. In fact, not only were the average $\mathrm{K}_{2}$ values of Rohrer equation fitted to the first $0.1 \mathrm{~s}$ of inspiration while breathing air on ZEEP significantly larger in Responders than in Non-responders (Table 6), but the individual values of $\mathrm{K}_{2}$ were significantly related to the changes of VIFL with heliox breathing (Figure 5), an even better correlation being found with changes of $\dot{\mathrm{V}} \mathrm{I}, \mathrm{pk}$ (slope $=1821 \pm 350 \mathrm{ml}^{3} \cdot \mathrm{s}^{-3} \cdot \mathrm{cmH}_{2} \mathrm{O}^{-1} ; \mathrm{R}^{2}=0.659 ; \mathrm{P}<0.001$ ). The values of $\mathrm{K}_{1}$ were negatively related to the changes of VIFL (Figure 5), but the slope of this relation, like that between $\mathrm{K}_{1}$ and $\dot{\mathrm{V}} \mathrm{I}$,pk changes (slope $=-50.3 \pm 25.6 \mathrm{ml}^{2} \cdot \mathrm{s}^{-2} \cdot \mathrm{cmH}_{2} \mathrm{O}^{-1} ; \mathrm{R}^{2}=0.005 ; \mathrm{P}=0.465$ ), was not significant. This suggests that $\mathrm{K}_{2}$ values assessed as described herein, even on the more easily obtainable -Pdyn- $\dot{\mathrm{V}}$ data, can be used to predict the occurrence of a positive response to heliox administration in the presence of tIFL.

Genioglossus muscle is the most effective among the pharyngeal dilator muscles and its activity is usually used as an index of the activation of this group of muscles. The prominent contribution of this muscle in preventing the onset of IFL and eventually upper airways occlusion in patients with obstructive sleep apnea is known since long (32), as well as the reflex origin of this activity (23). It has been suggested that in patients with OSA tonic activity of this muscle plays a major role in conferring greater stiffness to the collapsible segment $(16,21)$; but tonic activity was practically absent in the present animals, as it might be expected in anesthetized $(6,24)$ and sleeping animals $(28,30)$. Because the absolute level of genioglossus activation was not established in the present rabbits, e.g. Agg expressed relative to that with maximal hypoglossal nerve stimulation, it was not possible to relate the wide range of tracheal pressure at the onset of IFL (from -3.7 to -13.2 $\mathrm{cmH}_{2} \mathrm{O}$ ) to the measured phasic activity. This does not rule out the possibility that different genioglossal activation among animals might have participated in producing this wide range of pressures by acting on pharyngeal volume, shape, and elastance $(26,27)$. However, the level of genioglossal activity should have been substantial in these animals, because the critical upper airway closing pressure evaluated from VंI,pk and Ptr,I,pk while breathing on ZEEP and CPAP (Table 3) averaged $-25.8 \pm 7.9 \mathrm{cmH}_{2} \mathrm{O}$, that is about 3.5 times that directly recorded in rabbit isolated upper airway preparation $(26,27)$. On the other hand, the reflex nature of genioglossal activity and its dependence on upper airway pressure was demonstrated by the significant fall of Agg with CPAP, in line with previous observations in rabbits $(5,23)$, that was coupled to a significant increase of Adi, an estimate of the central inspiratory drive. This increase likely reflected the attempt to limit the fall of $\dot{V} E$ brought about by the decreased breathing frequency and the enhanced lung dynamic elastance with CPAP (Table 3). An additional evidence in favor of the mainly reflex 
nature of the genioglossal activity was the change of the Agg inspiratory profile from a ramp like on ZEEP to a descendent one on CPAP (Figure 2); in fact, a similar change is observed between occluded and unimpeded inspirations in both alae nasi and genioglossus muscle integrated activity of anesthetized, tracheostomized, spontaneously breathing dogs (36). Whatever the level of diaphragmatic and genioglossal activation might have been, heliox administration had no effect on these parameters both breathing on ZEEP and CPAP (Table 1 and 4). Moreover, no difference occurred between Responders and Non-responders in peak Agg,pk and Adi,pk, besides Agg and Adi at IFL onset, with heliox breathing. It appears, therefore, that the effects produced by heliox administration, as well as their discrepancies among animals (Table 2, 5, and 7) are independent of inspiratory muscle activation.

CPAP eliminated tIFL (Table 3) and promoted a substantial fall of upper airway resistance (Table 5). Suppression of tIFL has been also obtained in anesthetized, spontaneously breathing rabbits by means of an adequate activation of the genioglossus muscles via hypoglossal nerve stimulation (5). In contrast, heliox administration never produced this effect in the present animals. This might have been expected, because both CPAP and hypoglossal nerve stimulation act directly on the collapsible segment by increasing its caliber beyond that compatible with IFL, whereas the lateral pressure along the upper airways, and hence their caliber, should have remained nearly the same during both air and heliox breathing, at least judging from measured Ptr values (Table 1 and 3), besides those predicted by the model analysis (see below; Figure 6). Though very effective and rapid in eliminating tIFL, CPAP, even applied for appreciable times (10-15 min), did not exert any effect that might have prevented the reappearance or mitigated the severity of tIFL which resumed immediately and with the same characteristics as CPAP was removed (Table 3).

The pressure at which IFL took place (Ptr,on and Pdyn,on) was essentially the same during air and heliox breathing, independent of the magnitude of the increase of VIFL caused by heliox administration (Table 1 and 3). A similar occurrence was observed in various physical models of Starling resistors, in which, however, the increase of flow with heliox is always present, though of variable magnitude, depending on the geometrical and mechanical characteristics of the collapsible walls. In line with previous observations in patients with obstructive sleep apnea $(17,34)$, this indicates that the mechanism leading to tIFL in the present animals should be comparable to that operating in the Starling resistor, the level of the limited flow being set by the relative impact of laminar and turbulent flow. Furthermore, the similarity of the pressure-flow curves observed in these rabbits and in OSA patients $(7,29)$, suggests that the mechanisms leading to tIFL might be also the same. 
In half of the animals breathing on ZEEP heliox administration increased VIFL by $28.6 \pm 11.4 \%$ with peaks of $44-46 \%$, but in three animals the increase was as low as $2.3 \pm 0.5 \%$. In contrast, Ptr,I,pk and Ptr,on were essentially the same in animals which did or did not respond to heliox administration (Table 2). The relations shown in Figure 5 suggest that the wide variability in the changes of VIFL with heliox breathing among animals could be related to individual differences in the relative impact of viscous and turbulent flow regime. In an attempt to explain the presence of Responders and Non-responders to heliox administration (Table 2, 5 and 7), the respiratory tract between airway opening and the beginning of the trachea was depicted as three branches in series, with only the intermediate one being collapsible. The resistance of each branch was modeled as a non-linear resistor (20)

$$
\mathrm{R}=\frac{8 \cdot \pi \cdot \mu \cdot \mathrm{L}^{3}}{\mathrm{~V}^{2}}\left(\mathrm{~h}_{1}+\mathrm{h}_{2} \cdot \mathrm{Re}\right)
$$

where the first term represents the resistance due to laminar flow accounting for fluid viscosity $(\mu)$, length (L) and volume (V) of the branch, the second term the resistance bound to Reynolds number (Re), relevant when flow velocity is high and turbulence may occur, and $h_{1}$ and $h_{2}$ are dimensionless parameters that weight the contribution of the first and second term to the effective resistance of the branch. A detailed description of the mechanical and geometrical features of the model is provided in the Appendix.

As shown in Figure 6, the model simulation proved capable to reproduce the flow, volume, and tracheal pressure time course observed during air and heliox breathing at ZEEP in a typical Responder (case A) and Non-responder (case B), like those illustrated in Figure 2. This result was obtained by modifying between case $A$ and $B$ the parameters $h_{1}(13 \%)$ and $h_{2}(-88 \%)$, the length (67\%), and the transmural pressure-volume curve of the collapsible branch only (Table A1 and Figure A1). Because of these changes, during the time interval in which IFL occurs, the compliance and the diameter of the collapsible branch are always significantly higher and smaller, respectively, in Non-responders than in Responders, and considering that the length of the collapsible branch is even greater in Non-responders than in Responders, also the length-to-diameter ratio (L/D) is greater in the former group (Figure 7). Finally, it is worth to note that eq. 1 is similar to Rohrer equation, in which $\mathrm{K}_{1}$ and $\mathrm{K}_{2} \cdot \dot{\mathrm{V}}$ are analogous to the first and second term of eq.1; it is therefore reassuring that the modifications of $h_{1}$ and $h_{2}$ made to simulate case $A$ and $B$ (Table A1) were qualitatively similar to the differences in $K_{1}$ and $K_{2}$ between Responders and Non-responders obtained in fitting with Rohrer equation the pressure-flow data collected during the initial $0.1 \mathrm{~s}$ of inspiration (Table 6). 
Kreith and Eisenstadt (19) found that the flow rate through a short capillary tube can be related empirically to the overall pressure drop raised to a power $\alpha$, which is in turn a function of $\mathrm{L} / \mathrm{D}$; in the $\mathrm{L} / \mathrm{D}$ range $0.45-18, \alpha$ varies from 0.5 to 0.91 , tending to unity, i.e. the value for laminar flow, as L/D increases further. These findings justify the choice of the $h_{1}$ and $h_{2}$ values for the collapsible branch made to simulate case A and B (Table A1); in the former case, when L/D is around 7 (Figure 7), the weight of the turbulent component of the flow is important and suggests taking values of $h_{1}$ and $h_{2}$ similar to those indicated by Lambert et al. (20), whereas the $h_{1}$ and $h_{2}$ values chosen in the latter case are consistent with a L/D of about 13 (Figure 7), implying that the weight of the laminar component of the flow is increased while that of the turbulent component is significantly reduced. The positive outcome of the simulation indicates therefore that changes in both the pressure-volume curve and the length of the collapsible branch lead to a significant change in the L/D ratio, which strongly influences the flow characteristics in the branch itself and, as a consequence, the values of $h_{1}$ and $h_{2}$ in eq. 1 . This makes it possible to reproduce and interpret conditions in which heliox administration does or does not increase the inspiratory flow and tidal volume in the presence of tIFL.

In conclusion, heliox administration in anesthetized, normal rabbits exhibiting spontaneous inspiratory flow limitation, though unable to abolish tIFL, does increase inspiratory flow and tidal volume to an extent which is on average of functional relevance. The marked inter-individual differences in heliox response appear to be related to those in the geometrical and mechanical features of the collapsible segment of the upper airways, as shown by the model analysis, its results being similar to those obtained experimentally. Despite its relatively low complexity, the model seems to retain the main non-linear mechanical behavior of upper airway mechanics during IFL, and provides a convincing interpretation of the responses to heliox administration, that points to the relative contributions of laminar and turbulent flow to the pressure drop in the collapsible segment. Consistent with this conclusion, the ratio between $\mathrm{K}_{2}$ and $\mathrm{K}_{1}$ of Rohrer equation applied to the flowpressure data preceding the onset of IFL is found to be markedly greater in animals with a prominent increase of inspiratory flow and tidal volume when breathing heliox (Table 6), thus providing a potentially useful index for the expectation of positive outcomes. Obviously, it remains to be seen whether the results obtained in animals with spontaneous tIFL, altogether promising, have any therapeutic value in OSA patients and/or snorers.

In the present study, the evaluation of heliox administration was focused on the possible suppression of tIFL and/or the increase of inspiratory flow and tidal volume. It might be, however, that the most relevant effect of heliox administration is the prevention of IFL onset or the transition 
from partial to functionally complete obstruction of the upper airways. This could be the subject of further investigation.

\section{APPENDIX}

To model the response to heliox administration in spontaneously breathing rabbits with tIFL, the region between the airway opening and the beginning of the trachea was depicted as three branches in series, characterized by different mechanical and geometrical properties: upper branch (u), intermediate branch (i), and lower branch (1). The mechanical properties of the branches were described by non-linear relationships, related to flow characteristics, collapsibility of the airways, and inertial properties.

Each branch resistance was modeled as a nonlinear resistor described in the text by eq. 1 according to Lambert et al. (20).

Branch inertance was modeled as

$$
\mathrm{I}=\frac{\rho \cdot \mathrm{L}^{2}}{\mathrm{~V}}
$$

where $\rho$ is density.

Finally, it was assumed that the upper and lower branches of the airways did not significantly change their diameter and volume during the respiratory cycle, while the intermediate branch was assumed to be collapsible. This branch was represented as a cylinder of constant length, the volume of which depended on the transmural pressure $\left(\mathrm{P}_{\mathrm{tm}}\right)$ according to (3)

$$
\mathrm{V}=\frac{\mathrm{V}_{\max }}{1+\exp \left[-\mathrm{a}\left(\mathrm{P}_{\mathrm{tm}}-\mathrm{b}\right)\right]}
$$

where $\mathrm{V}_{\max }$ is the maximum volume of the branch, and $\mathrm{a}$ and $\mathrm{b}$ are constants.

The elastance $\mathrm{E}$ of the collapsible branch was obtained differentiating $\mathrm{P}_{\mathrm{tm}}$ with respect to $\mathrm{V}$

$$
\mathrm{E}=\frac{\mathrm{V}_{\max }}{\mathrm{aV}} \cdot \frac{1}{\mathrm{~V}_{\max }-\mathrm{V}}
$$

The pressure drop at the junction between two branches was described by the Bernoulli equation; assuming that the transition from one branch to the next occurred over a very short distance, friction losses should have been in fact negligible (20).

Using this model above, the lateral pressure $\mathrm{P}$ at the end of each branch was calculated as

$$
\mathrm{P}=\mathrm{P}_{\mathrm{A}}-\frac{1}{2} \rho \mathrm{U}^{2}-\Delta \mathrm{P}_{\text {vis }}-\Delta \mathrm{P}_{\text {in }}
$$


where $\mathrm{P}_{\mathrm{A}}$ is atmospheric pressure, $\mathrm{U}$ the mean flow speed in the branch, and $\Delta \mathrm{P}_{\text {vis }}$ and $\Delta \mathrm{P}_{\text {in }}$ are the total viscous and inertial pressure drops, respectively, from the airway opening to the end of the branch considered.

The order of magnitude of the geometric dimensions of the three airway branches of the model was derived from CT scans of the upper airways performed in one rabbit prepared as described by Olson et al. (27). Images were obtained with tracheal outlet pressure of zero or $-5 \mathrm{~cm}$ $\mathrm{H}_{2} \mathrm{O}$, thus allowing the identification of the collapsible segment.

Of the several simulations that mimicked the different responses to heliox administration observed experimentally in rabbits, two illustrative cases were presented in the text to show the behavior of a Responder (case A) and a Non-responder (case B) during air or heliox breathing. Taking case A as an example, Figure A1 shows a simple scale drawing of the three branches at the beginning of inspiration and at the time of maximum collapse during air breathing at ambient pressure. Table A1 reports the model parameters used to simulate the two cases, while Figure A2 shows the corresponding transmural pressure-volume curves of the collapsible branch. Based on the findings of Kreith and Eisenstadt (19), parameters $h_{1 i}$ and $h_{2 i}$ should have been made to change as a function of L/D. Nevertheless, these parameters were kept constant because L/D undergoes modest variations during IFL, as shown in Figure 7.

A final remark can be made concerning the simulation shown in Figure A3, where the flow curves refer to a case in which all parameters are identical to those of case $A$, except $h_{1 \mathrm{i}}$ and $\mathrm{h}_{2 \mathrm{i}}$ that are equal to those of case B. In fact, the behavior of a Responder was maintained despite the increase in $\mathrm{h}_{1 \mathrm{i}}$ and the simultaneous decrease in $\mathrm{h}_{2 \mathrm{i}}$, and the increase in inspiratory flow with heliox was only slightly less than that of case A in Figure 6. Hence, to be a Responder or a Non-responder depends also on the geometry (L and D) and on the pressure-volume curve of the collapsible tract, besides $h_{1 i}$ and $h_{2 i}$ values; in other words, the diversity of heliox responses is due to the combination of various geometric and mechanical factors.

The model was implemented in the MATLAB-SIMULINK software and the results were obtained using a variable-step solver for stiff problems. In each simulation, a number of breathing cycles was produced in order to reach the steady state, visually confirmed by superimposing flow $(\dot{\mathrm{V}})$, tracheal pressure $(\mathrm{Ptr})$, and volume $(\Delta \mathrm{V})$ time course, as in Figure 6. 


\section{DISCLOSURES}

No conflicts, financial or otherwise, are declared by the authors.

\section{AUTHOR CONTRIBUTIONS}

E.D. conceived and designed research; E.D. and M.P. performed experiments and analyzed data; P.B. and G.C. developed mathematical model and performed simulations, E.D. drafted manuscript; F.B., P.B., G.C., E.D. and M.P. edited, revised, and approved manuscript. 


\section{REFERENCES}

1. American Academy of Sleep Medicine Task Force. Sleep-related breathing disorders in adults: Recommendations for syndrome definition and measurement techniques in clinical research. Sleep 22: 667-688, 1999.

2. Barach AL. Use of helium as a therapeutic gas. Proc Soc Exp Bio Med 32: 462-464, 1934.

3. Barbini P, Cevenini G, Avanzolini G. Nonlinear mechanisms determining expiratory flow limitation in mechanical ventilation: a model-based interpretation. Ann Biomed Eng 31: 908916, 2003.

4. Baydur A, Behrakis PK, Zin WA, Jaeger M, Milic-Emili J. A simple method for assessing the validity of esophageal balloon technique. Am Rev Respir Dis 126: 788-791, 1982.

5. Bellemare F, Pecchiari M, Bandini M, Sawan M, D'Angelo E. Reversibility of airflow obstruction by hypoglossus nerve stimulation in anesthetized rabbits. Am J Respir Crit Care Med 172: 606-61, 2005.

6. Bennett FM, St John WM. Anesthesia selectively reduces hypoglossus nerve activity by actions upon the brain stem. Pflügers Arch 401: 421-423, 1984.

7. Bijaoui EL, Champagne V, Baconnier PF, Kimoff R, Bates JHT. Mechanical properties of the lung and upper airways in patients with sleep-disordered breathing. Am J Resp Crit Care Med 165: 1055-1061, 2002.

8. Bradley GW, von Euler C, Marttila I, Roos B. A model of the central and reflex inhibition of inspiration in the cat. Biol Cybernetics 19: 105-116, 1975.

9. Brouillette, RT, Thach BT. A neuromuscular mechanism maintaining extrathoracic airway patency. J Appl Physiol 46: 772-779, 1979.

10. Chevrolet, JC. Helium oxygen mixtures in the intensive care unit. Critical Care 5: 179$181,2001$.

11. D'Angelo E, Agostoni E. Immediate response to expiratory threshold loads. Respir Physiol 25: 269-284, 1975.

12. D'Angelo E. Central and direct vagal dependent control of expiratory duration in anaesthetized rabbits. Respir Physiol 34: 103-119, 1978.

13. D’Angelo E, Pecchiari M, Baraggia P, Saetta M, Balestro E, Milic-Emili J. Low-volume ventilation causes peripheral airway injury and increased airway resistance in normal rabbits. J Appl Physiol 92: 949-956, 2002. 
14. D’Angelo E, Calderini E, Tavola M, Pecchiari M. Standard and viscoelastic mechanical properties of respiratory system compartments in dogs: effect of volume, posture, and shape. Respir Physiol \& Neurobiol 261: 31-39, 2019.

15. Eisele DW, Smith PL, Alam DS, Schwartz AR. Direct hypoglossus nerve stimulation in obstructive sleep apnea. Arch Otolaryngol Head Neck Surg 123: 57-61, 1977.

16. Fogel RB, Malhotra A, Pillar G, Edwards JK, Beauregard J, Shea SA, White DP. Genioglossal activation in patients with obstructive sleep apnea versus control subjects. Am J Respir Crit Care Med 164: 2025-2039, 2001.

17. Gold AR, Schwartz AR. The pharingeal critical pressure. Chest 110: 1077-1088, 1996.

18. Kemper KJ, Ritz RH, Benson MS, Bishop MS. Helium-oxygen mixture in the treatment of postextubation stridor in pediatric trauma patients. Crit Care Med 19: 356-359, 1991.

19. Kreith F, Eisenstadt R. Pressure drop and flow characteristics of short capillary tubes at low Reynolds numbers. Trans Am Soc Mech Engineers 79: 1070-1078, 1957.

20. Lambert RK, Wilson TA, Hyatt RE, Rodarte JR. A computational model for expiratory flow. J Appl Physiol 52: 44-56, 1982.

21. Malhotra A, Fogel RB, Edwards JK, Shea SA, White DP. Local mechanisms drive genioglossus activation in obstructive sleep apnea. Am J Respir Crit Care Med 161: 1746$1749,2000$.

22. Manthous CA, Morgan S, Pohlman A, Hall JB. Heliox in the treatment of airflow obstruction: a critical review of the literature. Respir Care 42: 1034-1042, 1997.

23. Mathew OP, Abu-Osba YK, Thach BT. Influence of upper airway pressure changes on genioglossus muscle respiratory activity. J Appl Physiol 52: 438-444, 1982.

24. Mead J, Whittenberger JL. Physical properties of human lungs measured during spontaneous respiration. J Appl Physiol 5: 779-796, 1953.

25. Nishino T, Shirahata M, Yonezawa T, Honda Y. Comparison of changes in the hypoglossus and the phrenic nerve activity in response to increasing depth of anesthesia in cats. Anesthesiology 60: 19-24, 1984.

26. Olson LG, Ulmer LG, Saunders NA. Influence of muscle activity on the elastance of the upper airway of rabbits. J Appl Physiol 66: 755-759,1989.

27. Olson LG, Ulmer LG, Saunders NA. Pressure-volume properties of the upper airway of rabbits. J Appl Physiol 66: 759-763, 1989.

28. Orem J, Osorio I, Brooks E, Dick T. Activity of respiratory neurons during NREM sleep. J Neurophysiol 54: 1144-1156, 1985. 
29. Owens RL, Edwards BA, Sands SA, Butler JP, Eckert DJ, White DP, Malhotra A, Wellman A. Upper airway collapsibility and patterns of flow limitation at constant endexpiratory lung volume. J Appl Physiol 113: 691-699, 2012.

30. Parmeggiani PL, Sabattini L. Electromyographic aspect of postural respiratory and thermo-regulatory mechanisms in sleeping cats. Electroenceph clin Neurophysiol 33: 1-13, 1972.

31. Pecchiari M. Effects of heliox in stable COPD patients at rest and during exercise. Pulm Med 2012: 1-7 doi:10.1155/2012/593985.

32. Remmers JE, DEGroot WJ, Sauerland EK, Anch AM. Pathogenesis of upper airway occlusion during sleep. J Appl Physiol 44: 931-938, 1978.

33. Schwartz AR, Bennett ML, Smith PL, De Backer W, Hedner J, Boudewijns A, Van de Heyning P, Ejnell H, Hochban W, Knaack L, Podszus T, Penzel T, Peter JH, Goding GS, Erickson DJ, Testerman R, Ottenhoff F, Eisele DW. Therapeutic electrical stimulation of the hypoglossus nerve in obstructive sleep apnea. Arch Otolaryngol Head Neck Surg 127: 1216-1223, 2001.

34. Smith PL, Wise RA, Gold AR, Schwartz AR, Permutt S. Upper airway pressure-flow relationships in obstructive sleep apnea. J Appl Physiol 64, 789-795, 1988.

35. Sullivan CE, Issa FG, Berthon-Jones M, Eves L. Reversal of obstructive sleep apnoea by continuous positive airway pressure applied through the nares. The Lancet 317: 862865,1981 .

36. Van Lunteren E, Strohl KP, Parker DM, Bruce EN, Van dE Graaff WE, Cherniack NS. Phasic volume-related feedback on upper airway muscle activity. J Appl Physiol 56, 730$736,1984$.

37. Von Neergard K,Wirz K. Die messung der stromungswiederstande in der atemwedge des menchen, insbesondere bein asthma und emphysema. Z Klin Med 195: 51-82, 1927.

38. Weber JE, Chudnofsky CR, Younger JG, Larkin LG, Boczar M, Wilkerson MD, Zuriekat GY, Nolan B, Eicke DM. A randomized comparison of helium-oxygen mixture (heliox) and racemic epinephrine for the treatment of moderate to severe croup. Pediatrics 107: e96, 2001.

39. Woodson BT, Strohl KP, Soose RJ, Gillespie MB, Maurer JT, de Vries N, Padhya TA, Badr MS, Lin H, Vanderveken OM, Mickelson S, Strollo PJ. Upper airway stimulation for obstructive sleep apnea: 5-year outcomes. Otolaryngol Head Neck Surg 159: 194-202, 2018. 


\section{Legends}

Fig. 1. Flow $(\dot{\mathrm{V}})$, tracheal pressure $(\mathrm{Ptr})$, volume $(\Delta \mathrm{V})$ and esophageal pressure changes $(\Delta \mathrm{Pes})$ pertaining to the average breath (see Methods) of an intact rabbit breathing air at ambient pressure are shown as a function of time in the left panels. The vertical bars indicate onset and end of the inspiratory flow limitation, while the dotted line represents the elastic component $\left(\Delta \mathrm{V}_{(\mathrm{t})} \cdot \Delta \mathrm{PesT} / \mathrm{VT}\right)$ which subtracted to $\Delta \mathrm{Pes}_{(\mathrm{t})}$ gives the dynamic component (Pdyn) of transpulmonary pressure changes. The $\dot{\mathrm{V}}$-Ptr and $\dot{\mathrm{V}}$-Pdyn relationships pertaining to this average breath are shown in the right panels.

Fig. 2. Flow $(\dot{\mathrm{V}})$, tracheal pressure $(\mathrm{Ptr})$, volume $(\Delta \mathrm{V})$ and esophageal pressure changes $(\Delta \mathrm{Pes})$, and integrated electrical activity of the diaphragm (Adi) and genioglossus muscles (Agg) pertaining to the average breaths of two rabbits (A and B) during air (continuous line) or heliox breathing (dotted line) at ambient pressure or with continuous applied positive pressure (left or right panels in A and B).

Fig. 3. The relationships between tracheal (Ptr) or dynamic pressure (Pdyn) and flow (ن) during air (continuous line) or heliox breathing (dotted line) at ambient pressure or with continuous applied positive pressure (CPAP) in the two rabbits (A and B) of which the average breaths are shown in Fig. 2.

Fig. 4. The relationship between upper airway resistance preceding the onset of IFL (Rua) during air breathing and the heliox dependent changes in mean flow occurring during IFL (V்IFL) or peak inspiratory flow $(\dot{\mathrm{V}} \mathrm{I}, \mathrm{pk})$. Numbers indicate the slope $\pm \mathrm{SE}$ of the relationship.

Fig. 5 The relationship between $K_{1}$ or $K_{2}$ of Rohrer equation used to fit Ptr- $\dot{V}$ data pertaining to the first $0.1 \mathrm{~s}$ of inspiration during air breathing and the heliox dependent changes in mean flow occurring during IFL (V்IFL) in Responders (triangles) and Non-responders (circles). Numbers indicate the slope $\pm \mathrm{SE}$ of the relationship.

Fig. 6 Steady-state time course of flow $(\dot{V})$, tracheal pressure $(\mathrm{Ptr})$ and volume changes $(\Delta \mathrm{V})$ during air (continuous line) or heliox breathing (dotted line) at ambient pressure obtained by simulation to reproduce the records observed in a Responder (case A) and in a Non-responder (case B).

Fig. 7 Inspiratory time course of compliance (C), diameter (D), and the length-to-diameter ratio (L/D) of the collapsible branch occurring at steady-state in case A and B (Figure 6) during air (continuous line) or heliox breathing (dotted line). The horizontal bar indicate the period in which IFL is present.

Fig. A1 Scale representation of the model. The geometric proportions of the various branches refer to case A during air breathing at ambient pressure. The geometry of the collapsible branch is shown both at the beginning of inspiration (dotted cylinder) and at the time of maximum collapse (dark 
cylinder). The mechanical properties of each branch, described by non-linear relationships, related to flow characteristics, collapsibility of the airways, and inertial properties, are indicated using the electrical analogy. The Bernoulli equation was used to account for the pressure drops at the junctions between adjacent branches.

Fig. A2 Pressure-volume curve of the collapsible branch applied to case A (continuous line) and B (dotted line).

Fig. A3 Steady-state time course of flow (ن்) during air (continuous line) or heliox breathing (dotted line) at ambient pressure obtained by using the same parameters of case $A$ in Figure 6 , except $\mathrm{h}_{1 \mathrm{i}}$ and $\mathrm{h}_{2 \mathrm{i}}$ that were those applied to case B in Figure 6. 
Table 1. Breathing pattern and features of tidal inspiratory flow limitation (IFL) during air (AB) and heliox breathing (HB) in 22 anesthetized, spontaneously breathing rabbits.

\begin{tabular}{|c|c|c|c|c|}
\hline & $\mathrm{AB}$ & $\mathrm{HB}$ & $\Delta \mathrm{HB}-\mathrm{AB}$ & $\mathrm{p}$ \\
\hline VT, ml & $18.6 \pm 3.5$ & $20.7 \pm 3.4$ & $2.1 \pm 2.2$ & $<0.001$ \\
\hline TI, s & $0.61 \pm 0.11$ & $0.60 \pm 0.11$ & $-0.01 \pm 0.03$ & 0.034 \\
\hline TE, $\mathrm{s}$ & $1.04 \pm 0.31$ & $1.02 \pm 0.34$ & $-0.02 \pm 0.18$ & 0.632 \\
\hline $\mathrm{f}, 1 / \mathrm{min}$ & $38 \pm 10$ & $39 \pm 10$ & $1 \pm 4$ & 0.256 \\
\hline$\dot{\mathrm{V}} \mathrm{E}, \mathrm{ml} / \mathrm{min}$ & $716 \pm 248$ & $815 \pm 267$ & $100 \pm 127$ & 0.001 \\
\hline$\dot{\mathrm{V}} \mathrm{I}, \mathrm{pk}, \mathrm{ml} / \mathrm{s}$ & $35.9 \pm 10.0$ & $41.0 \pm 10.9$ & $5.1 \pm 4.5$ & $<0.001$ \\
\hline Ptr,I, pk, $\mathrm{cmH}_{2} \mathrm{O}$ & $-10.7 \pm 2.6$ & $-9.5 \pm 2.0$ & $1.2 \pm 1.5$ & 0.001 \\
\hline Pdyn,I, pk, $\mathrm{cmH}_{2} \mathrm{O}$ & $-11.5 \pm 3.0$ & $-10.0 \pm 2.1$ & $1.5 \pm 2.5$ & 0.005 \\
\hline Edyn, $\mathrm{cmH}_{2} \mathrm{O} / \mathrm{ml}$ & $0.32 \pm 0.19$ & $0.34 \pm 0.16$ & $0.01 \pm 0.12$ & 0.592 \\
\hline$\dot{\mathrm{V}} \mathrm{E}, \mathrm{pk}, \mathrm{ml} / \mathrm{s}$ & $-37.4 \pm 11.7$ & $-47.0 \pm 14.1$ & $-9.6 \pm 9.2$ & $<0.001$ \\
\hline Ptr,E, pk, $\mathrm{cmH}_{2} \mathrm{O}$ & $4.7 \pm 1.2$ & $4.8 \pm 1.1$ & $0.2 \pm 0.6$ & 0.196 \\
\hline Pdyn,E, pk, $\mathrm{cmH}_{2} \mathrm{O}$ & $5.5 \pm 1.5$ & $5.8 \pm 1.5$ & $0.3 \pm 0.7$ & 0.064 \\
\hline Adi, pk, a.u. & 1.00 & $0.99 \pm 0.07$ & $-0.01 \pm 0.07$ & 0.518 \\
\hline Agg, pk, a.u & 1.00 & $0.95 \pm 0.12$ & $-0.05 \pm 0.12$ & 0.078 \\
\hline$\dot{\mathrm{V}} \mathrm{IFL}, \mathrm{ml} / \mathrm{s}$ & $34.5 \pm 10.3$ & $39.9 \pm 11.2$ & $5.4 \pm 4.7$ & $<0.001$ \\
\hline $\mathrm{t}, \mathrm{on}, \mathrm{s}$ & $0.17 \pm 0.05$ & $0.17 \pm 0.05$ & $0.00 \pm 0.03$ & 0.880 \\
\hline$\Delta \mathrm{t}, \mathrm{s}$ & $0.35 \pm 0.11$ & $0.35 \pm 0.10$ & $-0.01 \pm 0.05$ & 0.531 \\
\hline V,on, s & $3.5 \pm 1.9$ & $3.8 \pm 2.0$ & $0.3 \pm 1.2$ & 0.199 \\
\hline$\Delta \mathrm{V}, \mathrm{ml}$ & $11.3 \pm 2.6$ & $12.3 \pm 2.8$ & $1.1 \pm 2.2$ & 0.075 \\
\hline$\dot{\mathrm{V}}, \mathrm{on}, \mathrm{ml} / \mathrm{s}$ & $35.2 \pm 10.0$ & $40.1 \pm 11.0$ & $4.9 \pm 4.6$ & $<0.001$ \\
\hline Ptr,on, $\mathrm{cmH}_{2} \mathrm{O}$ & $-7.2 \pm 2.3$ & $-6.8 \pm 2.1$ & $0.5 \pm 1.3$ & 0.101 \\
\hline Pdyn,on, $\mathrm{cmH}_{2} \mathrm{O}$ & $-7.5 \pm 2.2$ & $-7.1 \pm 2.2$ & $0.4 \pm 1.2$ & 0.128 \\
\hline Adi,on, a.u. & $0.50 \pm 0.10$ & $0.52 \pm 0.14$ & $0.02 \pm 0.14$ & 0.478 \\
\hline Agg,on, a.u & $0.85 \pm 0.13$ & $0.81 \pm 0.15$ & $-0.04 \pm 0.12$ & 0.137 \\
\hline
\end{tabular}

Values are mean \pm SD. VT: tidal volume; TI and TE: inspiratory and expiratory duration; f: breathing frequency; $\dot{V} E$ : pulmonary ventilation; $\dot{\mathrm{V}} \mathrm{I}, \mathrm{pk}$ and $\dot{\mathrm{V}} \mathrm{E}, \mathrm{pk}$ : peak inspiratory and expiratory flow; Ptr,I,pk and Ptr,E,pk: peak inspiratory and expiratory tracheal pressure; Pdyn,I,pk and Pdyn,E,pk: peak inspiratory and expiratory dynamic transpulmonary pressure; Edyn: dynamic elastance; Adi, pk and Agg, pk: peak diaphragmatic and genioglossus muscle activity; VIFL: mean flow during IFL; t,on: time of IFL onset; V,on, $\dot{V}$,on, Ptr,on, and Pdyn,on: volume, flow, tracheal and dynamic transpulmonary pressure at IFL onset; Adi,on and Agg,on: diaphragmatic and genioglossus muscle activity at IFL onset. 
Table 2. Breathing pattern and tidal inspiratory flow limitation (IFL) in anesthetized, spontaneously breathing rabbits in which a substantial difference $(\Delta)$ between air (AB) and heliox breathing (HB) did (Responders) or did not occur (Non-responders).

\begin{tabular}{|c|c|c|c|c|c|c|c|c|}
\hline & \multicolumn{3}{|c|}{ Responders $(\mathrm{N}=8)$} & \multicolumn{3}{|c|}{ Non-responders $(\mathrm{N}=8)$} & \multirow[b]{2}{*}{$p^{\dagger}$} & \multirow[b]{2}{*}{$\mathrm{p} \S$} \\
\hline & $\mathrm{AB}$ & $\Delta \mathrm{HB}-\mathrm{AB}$ & $\mathrm{p}^{*}$ & $\mathrm{AB}$ & $\Delta \mathrm{HB}-\mathrm{AB}$ & $\mathrm{p}^{*}$ & & \\
\hline VT, ml & $17.1 \pm 2.7$ & $4.3 \pm 2.0$ & $<0.001$ & $20.2 \pm 4.0$ & $0.7 \pm 1.0$ & 0.078 & $<0.001$ & 0.094 \\
\hline TI, s & $0.60 \pm 0.09$ & $-0.03 \pm 0.03$ & 0.023 & $0.65 \pm 0.07$ & $0.00 \pm 0.03$ & 0.998 & 0.086 & 0.224 \\
\hline TE, $s$ & $1.11 \pm 0.38$ & $-0.10 \pm 0.24$ & 0.288 & $0.98 \pm 0.23$ & $-0.02 \pm 0.10$ & 0.517 & 0.431 & 0.441 \\
\hline $\mathrm{f}, 1 / \mathrm{min}$ & $37 \pm 10$ & $4 \pm 4$ & 0.046 & $38 \pm 6$ & $1 \pm 3$ & 0.572 & 0.104 & 0.966 \\
\hline$\dot{\mathrm{V}} \mathrm{E}, \mathrm{ml} / \mathrm{min}$ & $630 \pm 155$ & $239 \pm 109$ & $<0.001$ & $759 \pm 195$ & $36 \pm 25$ & 0.005 & $<0.001$ & 0.165 \\
\hline$\dot{\mathrm{V}} \mathrm{I}, \mathrm{pk}, \mathrm{ml} / \mathrm{s}$ & $33.3 \pm 5.1$ & $9.9 \pm 4.0$ & $<0.001$ & $35.4 \pm 8.3$ & $1.6 \pm 0.8$ & 0.001 & $<0.001$ & 0.549 \\
\hline Ptr,I, pk, $\mathrm{cmH}_{2} \mathrm{O}$ & $-10.6 \pm 2.8$ & $1.9 \pm 2.1$ & 0.040 & $-10.6 \pm 2.9$ & $0.7 \pm 1.5$ & 0.256 & 0.115 & 0.989 \\
\hline $\mathrm{Pdyn}, \mathrm{I}, \mathrm{pk}, \mathrm{cmH}_{2} \mathrm{O}$ & $-11.6 \pm 4.0$ & $2.6 \pm 3.1$ & 0.051 & $-11.3 \pm 2.8$ & $0.6 \pm 1.5$ & 0.284 & 0.078 & 0.851 \\
\hline Edyn, $\mathrm{cmH}_{2} \mathrm{O} / \mathrm{ml}$ & $0.31 \pm 0.22$ & $0.04 \pm 0.18$ & 0.557 & $0.32 \pm 0.18$ & $-0.01 \pm 0.11$ & 0.845 & 0.537 & 0.906 \\
\hline$\dot{\mathrm{V}} \mathrm{E}, \mathrm{pk}, \mathrm{ml} / \mathrm{s}$ & $-31.4 \pm 7.7$ & $-19.2 \pm 7.7$ & $<0.001$ & $-41.2 \pm 11.6$ & $-4.2 \pm 4.7$ & 0.040 & $<0.001$ & 0.066 \\
\hline Ptr,E, pk, $\mathrm{cmH}_{2} \mathrm{O}$ & $4.3 \pm 1.4$ & $0.1 \pm 0.6$ & 0.541 & $4.9 \pm 1.1$ & $0.4 \pm 0.7$ & 0.154 & 0.459 & 0.422 \\
\hline $\mathrm{Pdyn}, \mathrm{E}, \mathrm{pk}, \mathrm{cmH}_{2} \mathrm{O}$ & $5.1 \pm 1.7$ & $0.3 \pm 1.0$ & 0.396 & $5.7 \pm 1.4$ & $0.5 \pm 0.7$ & 0.073 & 0.669 & 0.444 \\
\hline Adi, pk, a.u. & 1.00 & $-0.05 \pm 0.08$ & 0.152 & 1.00 & $0.02 \pm 0.04$ & 0.215 & 0.060 & \\
\hline Agg, pk, a.u & 1.00 & $-0.06 \pm 0.14$ & 0.265 & 1.00 & $-0.02 \pm 0.08$ & 0.567 & 0.466 & \\
\hline$\dot{\mathrm{V}} \mathrm{IFL}, \mathrm{ml} / \mathrm{s}$ & $31.5 \pm 5.4$ & $10.7 \pm 3.8$ & $<0.001$ & $34.6 \pm 7.7$ & $1.8 \pm 0.7$ & $<0.001$ & $<0.001$ & 0.339 \\
\hline t,on, s & $0.17 \pm 0.06$ & $0.00 \pm 0.03$ & 0.678 & $0.18 \pm 0.04$ & $0.00 \pm 0.03$ & 0.756 & 0.601 & 0.744 \\
\hline$\Delta \mathrm{t}, \mathrm{s}$ & $0.34 \pm 0.05$ & $-0.03 \pm 0.04$ & 0.132 & $0.37 \pm 0.10$ & $-0.01 \pm 0.04$ & 0.558 & 0.434 & 0.523 \\
\hline V,on, s & $3.2 \pm 1.9$ & $0.5 \pm 1.5$ & 0.364 & $4.0 \pm 1.5$ & $0.3 \pm 0.9$ & 0.454 & 0.666 & 0.373 \\
\hline$\Delta \mathrm{V}, \mathrm{ml}$ & $10.7 \pm 0.9$ & $2.5 \pm 1.9$ & 0.008 & $12.1 \pm 3.9$ & $1.1 \pm 2.3$ & 0.227 & 0.196 & 0.332 \\
\hline$\dot{\text { Von, }} \mathrm{ml} / \mathrm{s}$ & $32.7 \pm 5.3$ & $9.7 \pm 3.7$ & $<0.001$ & $35.0 \pm 8.3$ & $1.3 \pm 0.6$ & 0.001 & $<0.001$ & 0.524 \\
\hline Ptr,on, $\mathrm{cmH}_{2} \mathrm{O}$ & $-6.9 \pm 2.5$ & $0.6 \pm 1.5$ & 0.298 & $-7.7 \pm 2.8$ & $0.5 \pm 1.1$ & 0.273 & 0.827 & 0.573 \\
\hline Pdyn,on, $\mathrm{cmH}_{2} \mathrm{O}$ & $-7.2 \pm 1.7$ & $0.3 \pm 1.1$ & 0.487 & $-8.3 \pm 2.8$ & $0.4 \pm 1.0$ & 0.324 & 0.850 & 0.163 \\
\hline Adi, pk, a.u. & $0.52 \pm 0.10$ & $-0.07 \pm 0.11$ & 0.119 & $0.47 \pm .05$ & $0.11 \pm 0.16$ & 0.088 & 0.519 & 0.283 \\
\hline Agg, pk, a.u & $0.89 \pm 0.06$ & $-0.08 \pm 0.14$ & 0.140 & $0.81 \pm 0.18$ & $-0.04 \pm 0.12$ & 0.391 & 0.114 & 0.240 \\
\hline
\end{tabular}

Values are mean \pm SD. Abbreviations as in Table 1. *significance of $\Delta \mathrm{HB}-\mathrm{AB}$; †comparison of $\Delta \mathrm{HB}-\mathrm{AB}$ between Responders and Non-responders; §comparison between Responders and Non-responders during AB. 
Table 3. Breathing pattern and tidal inspiratory flow limitation (IFL) in 12 anesthetized, spontaneously rabbits during air (AB) and heliox breathing (HB) at ambient (ZEEP) or elevated pressure (CPAP).

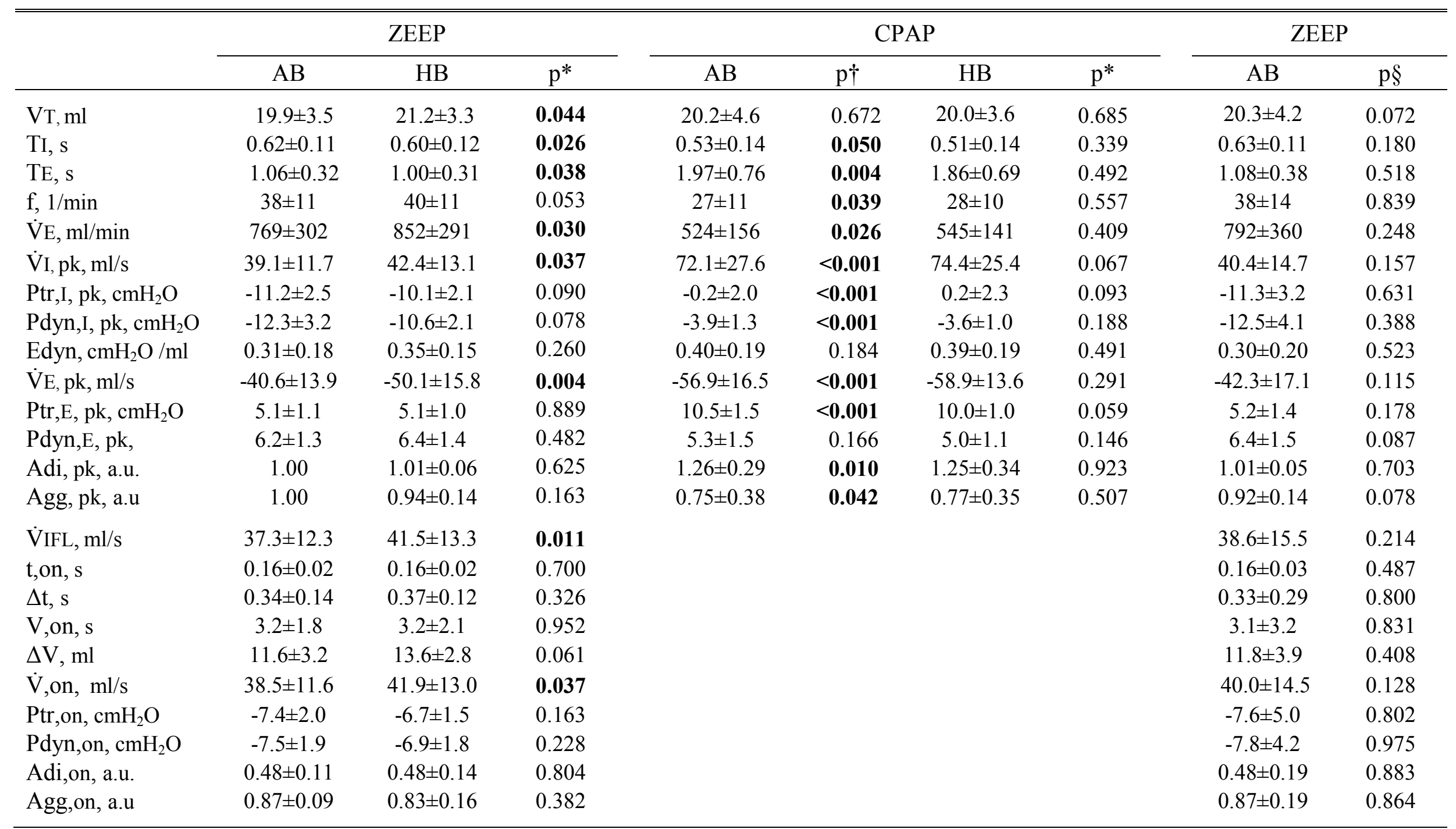

Values are mean \pm SD. Abbreviations as in Table 1. *comparison between $\mathrm{HB}$ and $\mathrm{AB} ; \uparrow$ comparison between ZEEP and CPAP on AB; $\S$ comparison between $\mathrm{AB}$ on ZEEP before and after CPAP. 
Table 4. Inspiratory and expiratory resistance during air (AB) and heliox breathing (HB) at ambient pressure in all rabbits and in Responders and Non-responders.

\begin{tabular}{|c|c|c|c|c|c|c|c|c|c|c|}
\hline & \multicolumn{3}{|c|}{$\underset{(\mathrm{N}=22)}{\text { All animals }}$} & \multicolumn{3}{|c|}{$\begin{array}{l}\text { Responders } \\
\qquad(\mathrm{N}=8)\end{array}$} & \multicolumn{3}{|c|}{$\begin{array}{c}\text { Non-responders } \\
\qquad(\mathrm{N}=8)\end{array}$} & \multirow[b]{2}{*}{$\mathrm{p}_{\dagger}^{\dagger}$} \\
\hline & $\mathrm{AB}$ & HB & $\mathrm{p}^{*}$ & $\mathrm{AB}$ & $\mathrm{HB}$ & $\mathrm{p}^{*}$ & $\mathrm{AB}$ & $\mathrm{HB}$ & p* & \\
\hline \multicolumn{11}{|l|}{ Inspiration } \\
\hline $\mathrm{RL}, \mathrm{cmH}_{2} \mathrm{O} \cdot \mathrm{s} \cdot \mathrm{ml}^{-1}$ & $0.140 \pm 0.054$ & $0.124 \pm 0.048$ & 0.017 & $0.146 \pm 0.055$ & $0.110 \pm 0.040$ & 0.012 & $0.136 \pm 0.039$ & $0.139 \pm 0.052$ & 0.589 & 0.708 \\
\hline $\mathrm{Rla}, \mathrm{cmH}_{2} \mathrm{O} \cdot \mathrm{s} \cdot \mathrm{ml}^{-1}$ & $0.015 \pm 0.008$ & $0.017 \pm 0.010$ & 0.263 & $0.018 \pm 0.010$ & $0.019 \pm 0.013$ & 0.361 & $0.014 \pm 0.005$ & $0.016 \pm 0.008$ & 0.503 & 0.456 \\
\hline Rua, $\mathrm{cmH}_{2} \mathrm{O} \cdot \mathrm{s} \cdot \mathrm{ml}^{-1}$ & $0.123 \pm 0.046$ & $0.111 \pm 0.040$ & 0.011 & $0.131 \pm 0.042$ & $0.106 \pm 0.034$ & 0.016 & $0.122 \pm 0.045$ & $0.121 \pm 0.045$ & 0.899 & 0.662 \\
\hline $\mathrm{RL}, \mathrm{cmH}_{2} \mathrm{O} \cdot \mathrm{s} \cdot \mathrm{ml}^{-1}$ & $0.146 \pm 0.049$ & $0.136 \pm 0.043$ & 0.047 & $0.158 \pm 0.045$ & $0.135 \pm 0.040$ & 0.019 & $0.142 \pm 0.043$ & $0.147 \pm 0.043$ & 0.322 & 0.467 \\
\hline $\mathrm{Rla}, \mathrm{cmH}_{2} \mathrm{O} \cdot \mathrm{s} \cdot \mathrm{ml}^{-1}$ & $0.023 \pm 0.016$ & $0.025 \pm 0.020$ & 0.096 & $0.027 \pm 0.024$ & $0.028 \pm 0.028$ & 0.644 & $0.020 \pm 0.011$ & $0.025 \pm 0.017$ & 0.125 & 0.474 \\
\hline
\end{tabular}

Values are mean \pm SD. R: resistance of the upper (ua) and lower airways (la), and of the lung (L). Rla includes lung tissue resistance (see Methods).

Inspiratory resistance refers to the part preceding the onset of inspiratory low limitation. * comparison between $\mathrm{AB}$ and $\mathrm{HB} \uparrow$ comparison between Responders and Non-responders during AB. 
Table 5. Inspiratory and expiratory resistance during air breathing (AB) at ambient pressure (ZEEP) before and after sustained application of continuous positive pressure (CPAP), and during air and heliox breathing (HB) with CPAP in 12 rabbits.

\begin{tabular}{|c|c|c|c|c|c|c|c|c|c|}
\hline & \multicolumn{3}{|c|}{ ZEEP } & \multicolumn{4}{|c|}{ CPAP } & \multicolumn{2}{|c|}{ ZEEP } \\
\hline & $\mathrm{AB}$ & HB & $\mathrm{p}^{*}$ & $\mathrm{AB}$ & $\mathrm{p} \dagger$ & HB & $\mathrm{p}^{*}$ & $\mathrm{AB}$ & $\mathrm{p} \S$ \\
\hline \multicolumn{10}{|c|}{ Inspiration } \\
\hline Rua, $\mathrm{cmH}_{2} \mathrm{O} \cdot \mathrm{s} \cdot \mathrm{ml}^{-1}$ & $0.121 \pm 0.046$ & $0.102 \pm 0.037$ & 0.046 & $0.097 \pm 0.052$ & 0.022 & $0.083 \pm 0.034$ & 0.787 & $0.125 \pm 0.042$ & 0.552 \\
\hline $\mathrm{RL}, \mathrm{cmH}_{2} \mathrm{O} \cdot \mathrm{s} \cdot \mathrm{ml}^{-1}$ & $0.136 \pm 0.051$ & $0.117 \pm 0.039$ & 0.049 & $0.107 \pm 0.052$ & 0.034 & $0.094 \pm 0.059$ & 0.708 & $0.143 \pm 0.049$ & 0.271 \\
\hline $\mathrm{Rla}, \mathrm{cmH}_{2} \mathrm{O} \cdot \mathrm{s} \cdot \mathrm{ml}^{-1}$ & $0.014 \pm 0.010$ & $0.014 \pm 0.009$ & 0.396 & $0.010 \pm 0.005$ & 0.254 & $0.011 \pm 0.029$ & 0.456 & $0.019 \pm 0.009$ & 0.188 \\
\hline \multicolumn{10}{|c|}{ Expiration } \\
\hline Rua, $\mathrm{cmH}_{2} \mathrm{O} \cdot \mathrm{s} \cdot \mathrm{ml}^{-1}$ & $0.116 \pm 0.047$ & $0.108 \pm 0.043$ & 0.122 & $0.078 \pm 0.041$ & 0.015 & $0.066 \pm 0.027$ & 0.662 & $0.121 \pm 0.044$ & 0.575 \\
\hline $\mathrm{RL}, \mathrm{cmH}_{2} \mathrm{O} \cdot \mathrm{s} \cdot \mathrm{ml}^{-1}$ & $0.141 \pm 0.052$ & $0.136 \pm 0.048$ & 0.288 & $0.091 \pm 0.047$ & 0.013 & $0.083 \pm 0.032$ & 0.467 & $0.147 \pm 0.053$ & 0.555 \\
\hline $\mathrm{Rla}, \mathrm{cmH}_{2} \mathrm{O} \cdot \mathrm{s} \cdot \mathrm{ml}^{-1}$ & $0.025 \pm 0.017$ & $0.028 \pm 0.018$ & 0.212 & $0.013 \pm 0.011$ & 0.079 & $0.016 \pm 0.014$ & 0.474 & $0.026 \pm 0.019$ & 0.825 \\
\hline
\end{tabular}

Values are mean \pm SD. On ZEEP, inspiratory resistance refers to the part preceding the onset of inspiratory low limitation. Abbreviations as in Table 4.* comparison between $\mathrm{AB}$ and $\mathrm{HB} \uparrow$ comparison between ZEEP and CPAP during AB; $\S$ comparison between AB on ZEEP before and after 15 min on CPAP. 
Table 6. $\mathrm{K}_{1}$ and $\mathrm{K}_{2}$ of Rohrer equation fitted to $\mathrm{P}-\dot{\mathrm{V}}$ data obtained during the first $0.1 \mathrm{~s}$ of inspiration before the onset of inspiratory flow limitation during air breathing at ambient pressure in 16 rabbits which did or did not respond to heliox administration.

\begin{tabular}{lccr}
\hline \hline & $\begin{array}{c}\text { Responders } \\
(\mathrm{N}=8)\end{array}$ & $\begin{array}{c}\text { Non-responders } \\
(\mathrm{N}=8)\end{array}$ & \multicolumn{1}{c}{$\mathrm{p}^{*}$} \\
\hline \multicolumn{1}{c}{$\mathbf{- P t r}-\dot{\mathbf{V}}$} & & & \\
$\mathrm{K}_{1}, \mathrm{cmH}_{2} \mathrm{O} \cdot \mathrm{s} \cdot \mathrm{ml}^{-1}$ & $0.042 \pm 0.029$ & $0.083 \pm 0.054$ & 0.082 \\
$\mathrm{~K}_{2}, \mathrm{cmH}_{2} \mathrm{O} \cdot \mathrm{s}^{2} \cdot \mathrm{ml}^{-2}$ & $0.005 \pm 0.002$ & $0.002 \pm 0.001$ & $<\mathbf{0 . 0 0 1}$ \\
$\mathrm{Rua}, \mathrm{cmH}_{2} \mathrm{O} \cdot \mathrm{s} \cdot \mathrm{ml}^{-1}$ & $0.124 \pm 0.053$ & $0.113 \pm 0.050$ & 0.676 \\
\multicolumn{1}{c}{$-\mathbf{P d y n}-\dot{\mathbf{V}}$} & & & \\
$\mathrm{K}_{1}, \mathrm{cmH}_{2} \mathrm{O} \cdot \mathrm{s} \cdot \mathrm{ml}^{-1}$ & $0.035 \pm 0.035$ & $0.083 \pm 0.060$ & 0.071 \\
$\mathrm{~K}_{2}, \mathrm{cmH}_{2} \mathrm{O} \cdot \mathrm{s}^{2} \cdot \mathrm{ml}^{-2}$ & $0.004 \pm 0.002$ & $0.002 \pm 0.001$ & $\mathbf{0 . 0 3 8}$ \\
$\mathrm{RL}, \mathrm{cmH}_{2} \mathrm{O} \cdot \mathrm{s} \cdot \mathrm{ml}^{-1}$ & $0.136 \pm 0.055$ & $0.118 \pm 0.056$ & 0.532
\end{tabular}

Values are mean \pm SD. R: average upper airway (ua) and transpulmonary resistance (L) during the same period used to assess the constants in Rohrer equation. * comparison between Responders and Non-responders. 
Table A1. Parameters of the non-linear model used to represent the upper airways and to simulate a positive (case A: Responders) or a negative response to heliox administration (case B: Nonresponder).

\begin{tabular}{|c|c|c|}
\hline Parameter & Case A & Case B \\
\hline $\mathrm{L}_{\mathrm{u}}, \mathrm{cm}$ & 6.0 & 6.0 \\
\hline $\mathrm{V}_{\mathrm{u}}, \mathrm{ml}$ & 0.8 & 0.8 \\
\hline $\mathrm{h}_{1 \mathrm{u}}$ & 3.40 & 3.40 \\
\hline $\mathrm{h}_{2 \mathrm{u}}$ & $2.10 \cdot 10^{-3}$ & $2.10 \cdot 10^{-3}$ \\
\hline $\mathrm{L}_{\mathrm{i}}, \mathrm{cm}$ & 0.6 & 1.0 \\
\hline $\mathrm{V}_{\max }, \mathrm{ml}$ & 0.025 & 0.020 \\
\hline $\mathrm{a}, \mathrm{cm} \mathrm{H}_{2} \mathrm{O}^{-1}$ & 0.031 & 0.050 \\
\hline $\mathrm{b}, \mathrm{cm} \mathrm{H}_{2} \mathrm{O}$ & 41.0 & 6.6 \\
\hline $\mathrm{h}_{1 \mathrm{i}}$ & 4.81 & 5.44 \\
\hline $\mathrm{h}_{2 \mathrm{i}}$ & $2.10 \cdot 10^{-3}$ & $0.252 \cdot 10^{-3}$ \\
\hline $\mathrm{L}_{\mathrm{l}}, \mathrm{cm}$ & 1.2 & 1.2 \\
\hline $\mathrm{V}_{\mathrm{l}}, \mathrm{ml}$ & 0.6 & 0.6 \\
\hline $\mathrm{h}_{11}$ & 3.40 & 3.40 \\
\hline $\mathrm{h}_{21}$ & $2.10 \cdot 10^{-3}$ & $2.10 \cdot 10^{-3}$ \\
\hline$\rho_{\text {air }}, \mathrm{g} \cdot \mathrm{ml}^{-1}$ & \multicolumn{2}{|c|}{$1138 \cdot 10^{-6}$} \\
\hline$\rho_{\text {heliox }}, \mathrm{g} \cdot \mathrm{ml}^{-1}$ & \multicolumn{2}{|c|}{$3150 \cdot 10^{-6}$} \\
\hline$\mu_{\mathrm{air}}$, poise & \multicolumn{2}{|c|}{$1875 \cdot 10^{-7}$} \\
\hline$\mu_{\text {heliox }}$, poise & \multicolumn{2}{|c|}{$2243 \cdot 10^{-7}$} \\
\hline
\end{tabular}

Symbols as in eq. 1A, 2A, and 3A. The subscript $\mathrm{u}$, i, and 1 indicate the upper, intermediate, and lower branch of the model 

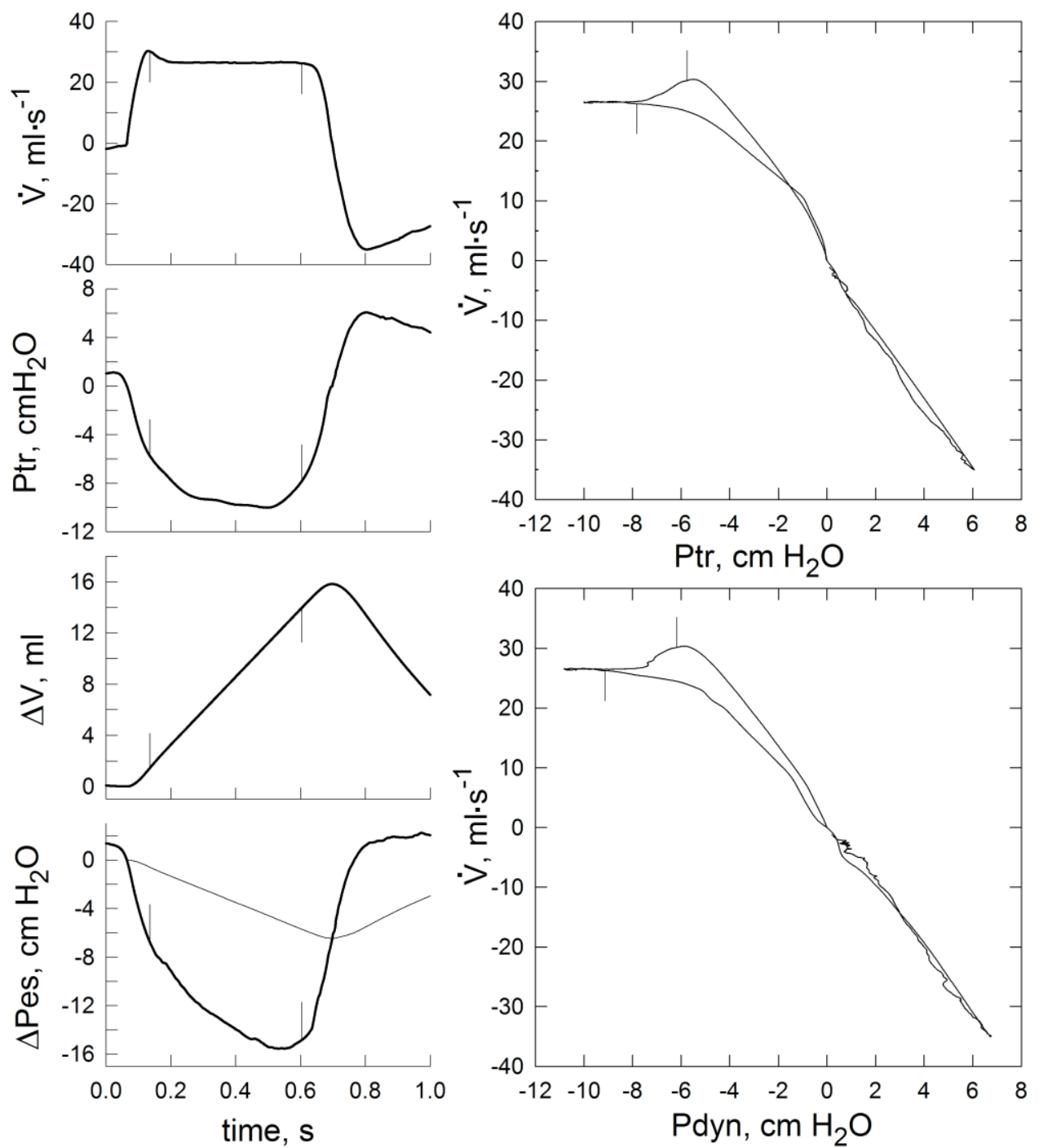

Figure 1 

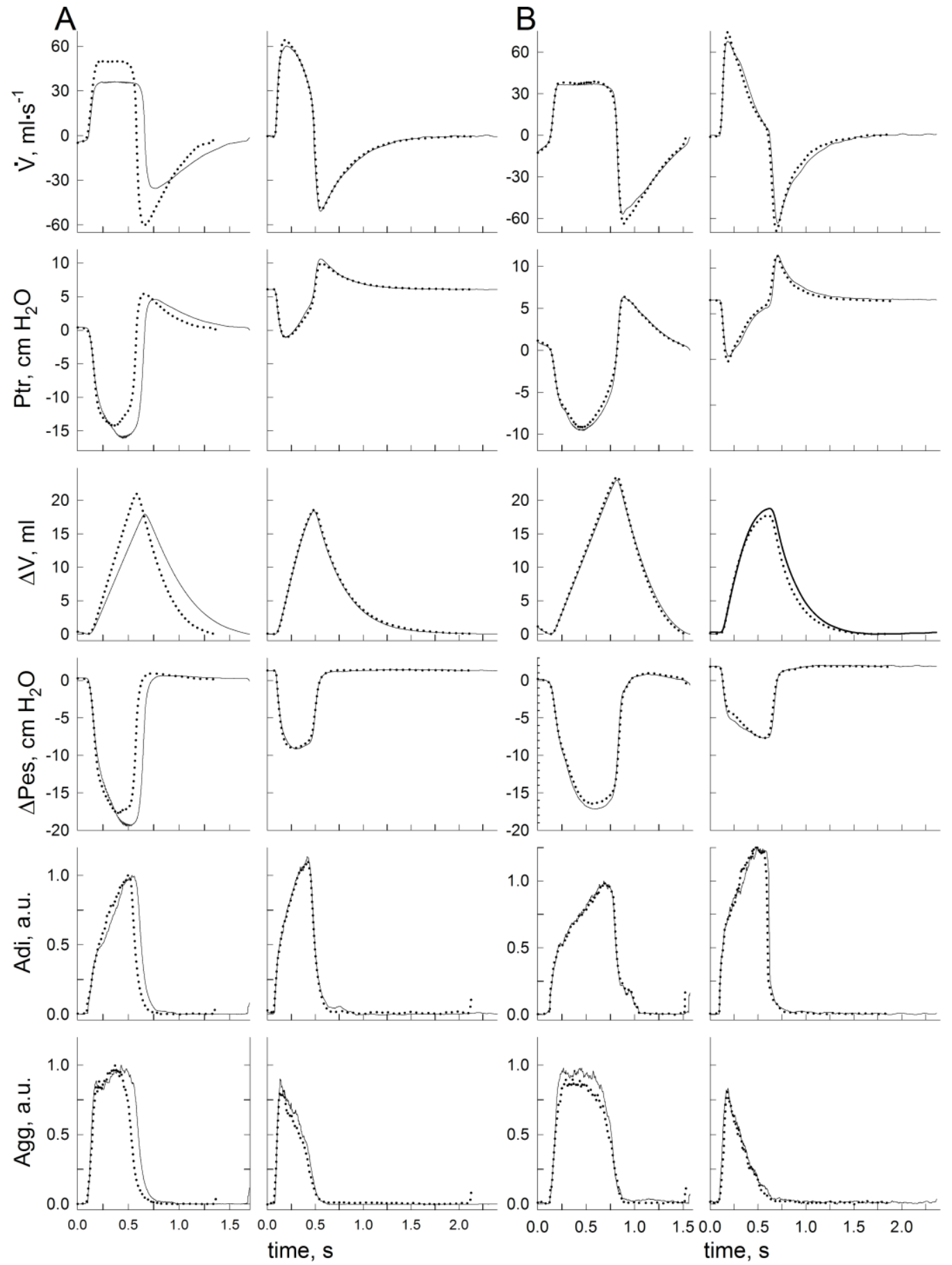

Figure 2 

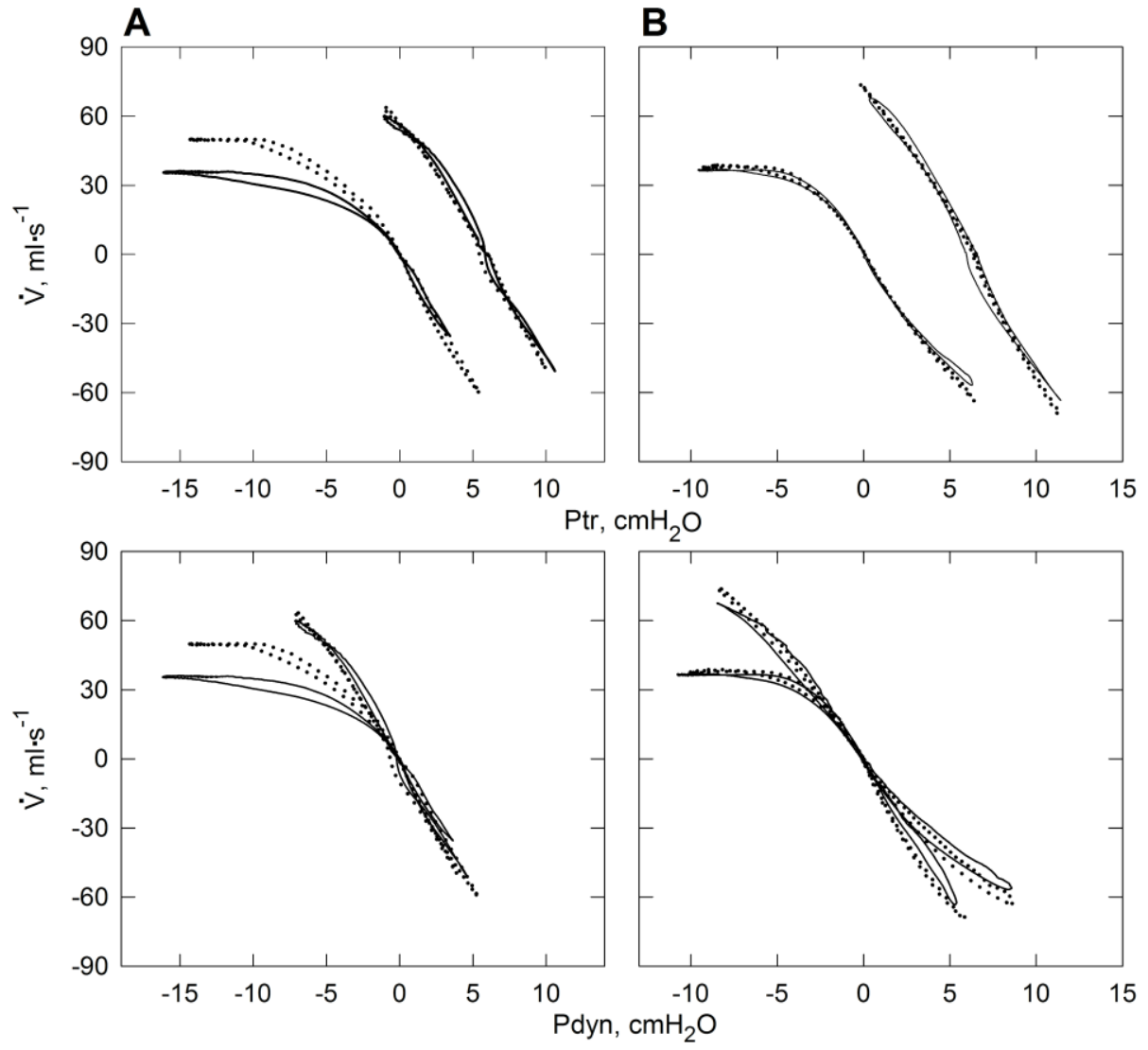

Figure 3 

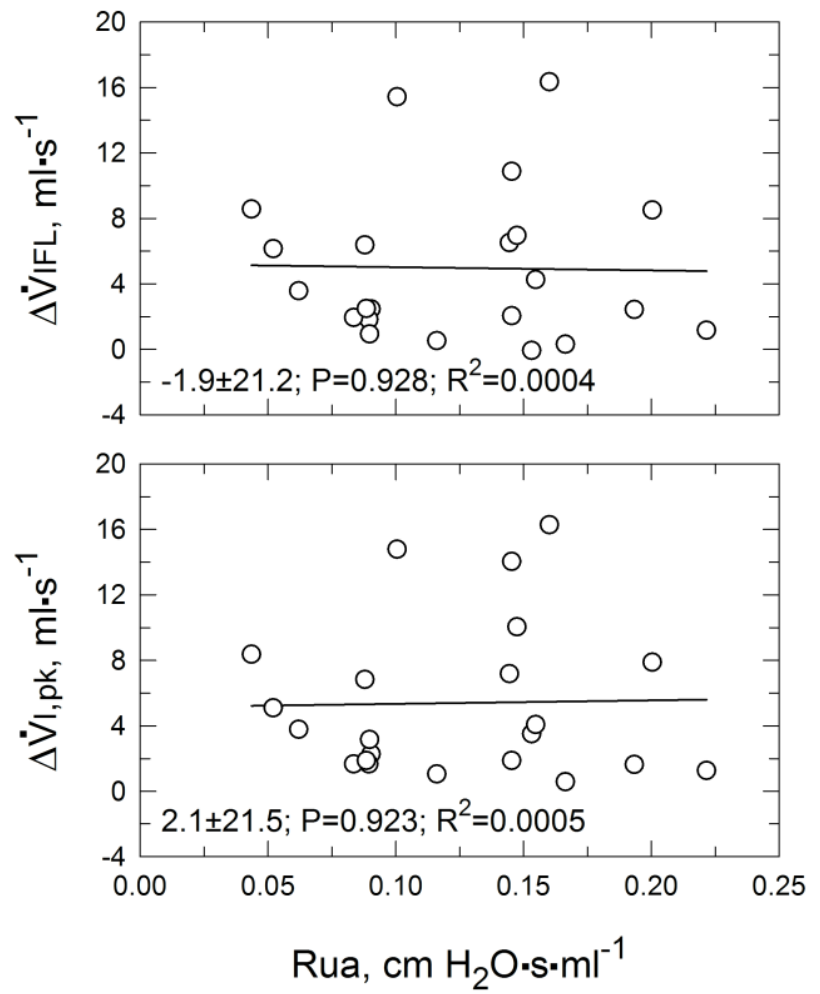

Figure 4 

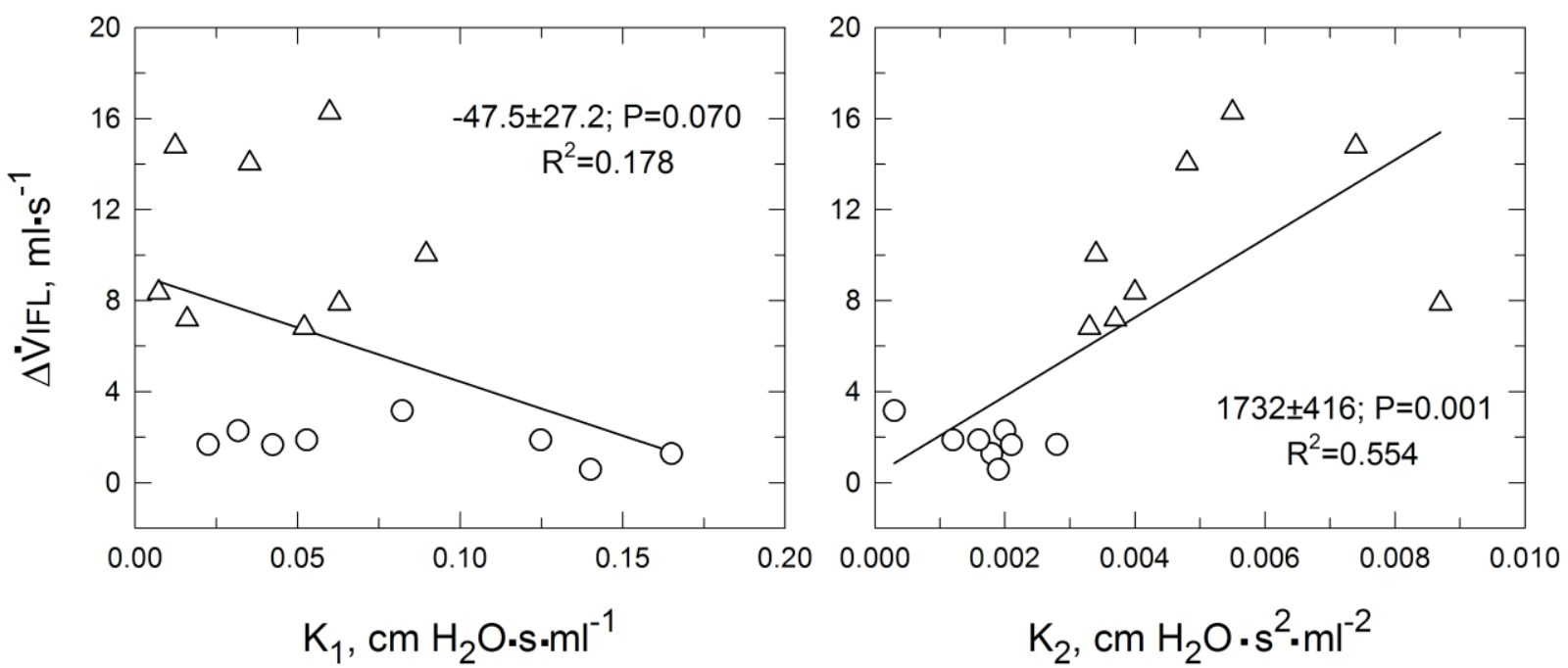

Figure 5 

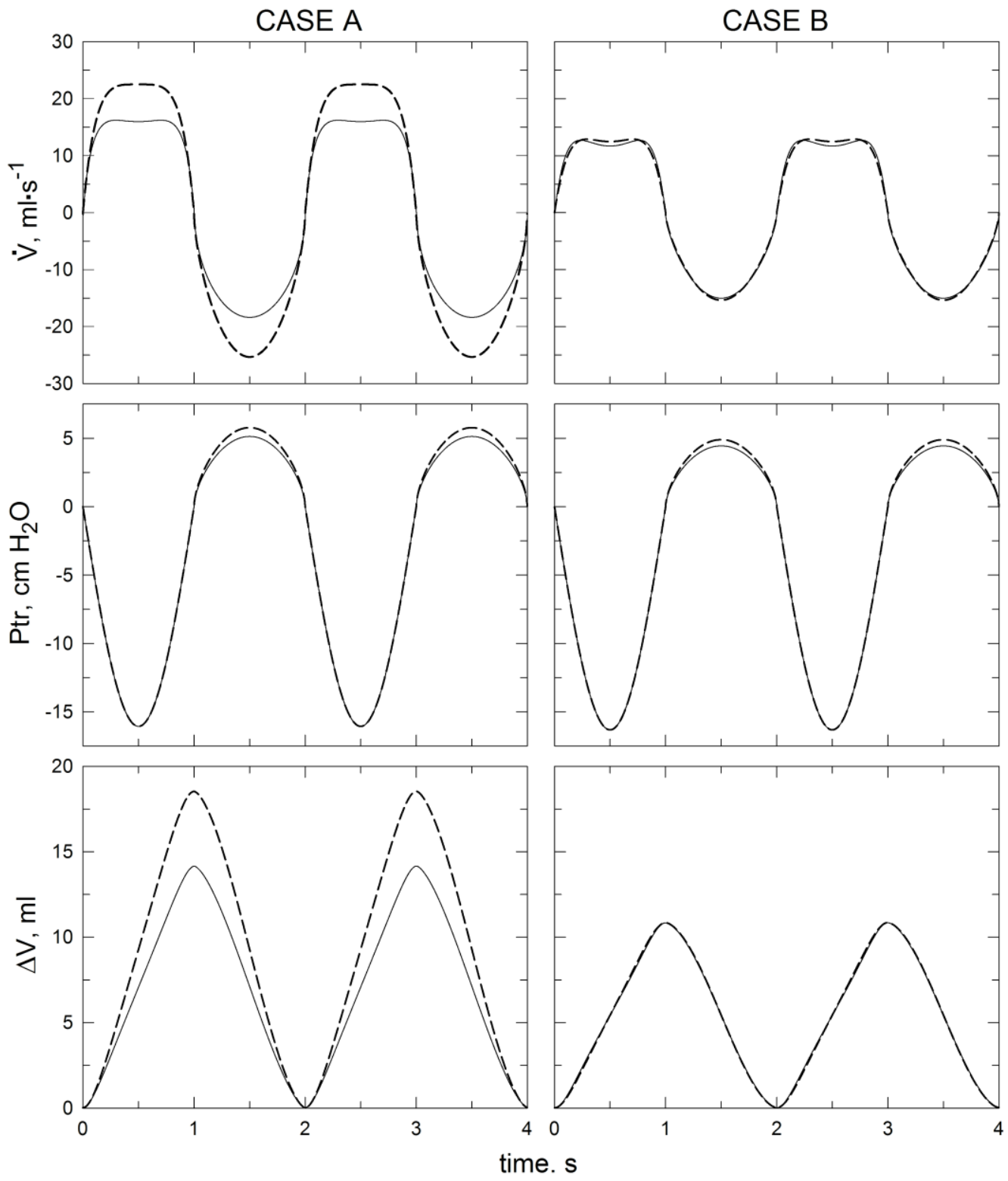

Figure 6 


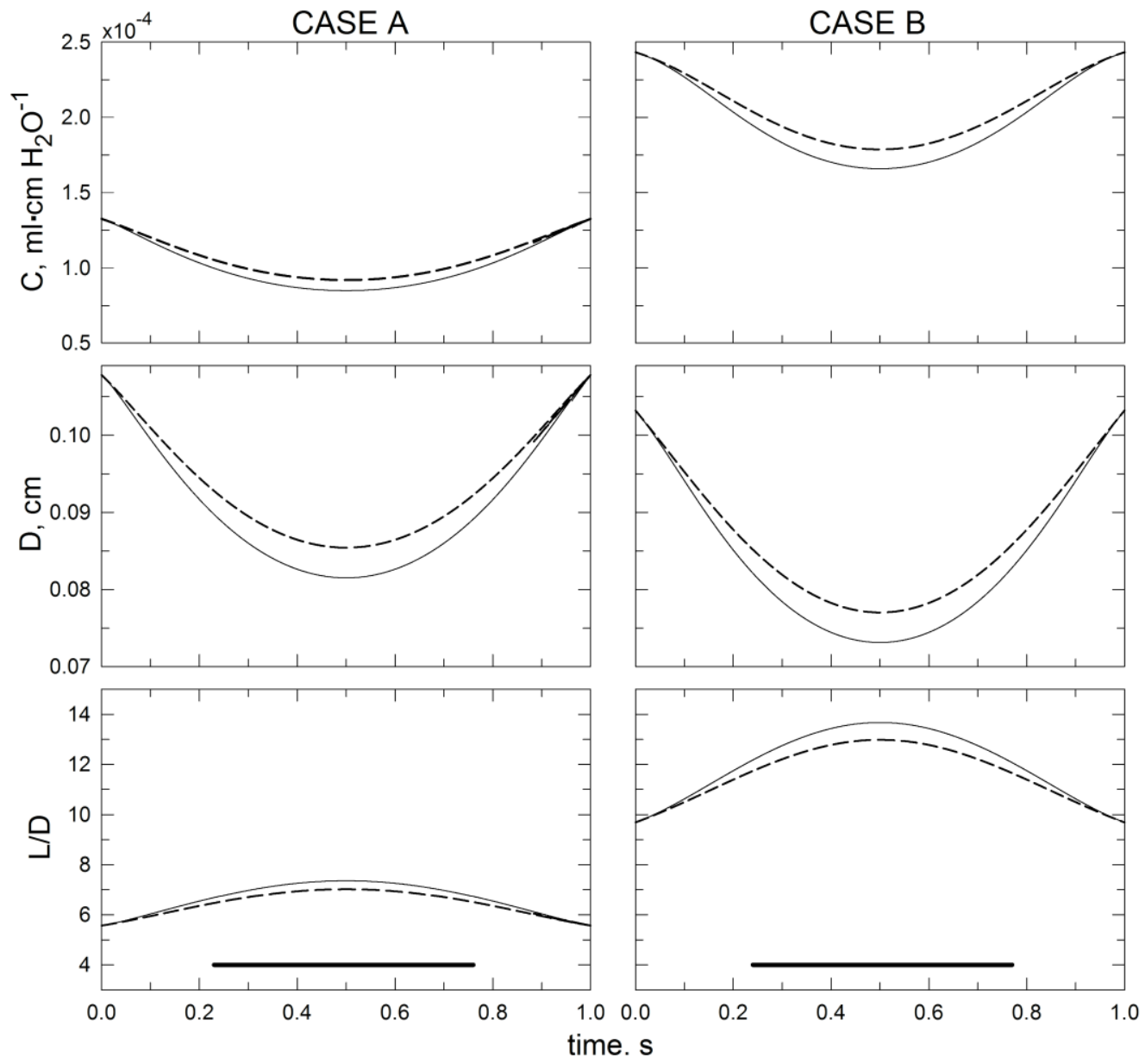

Figure 7 


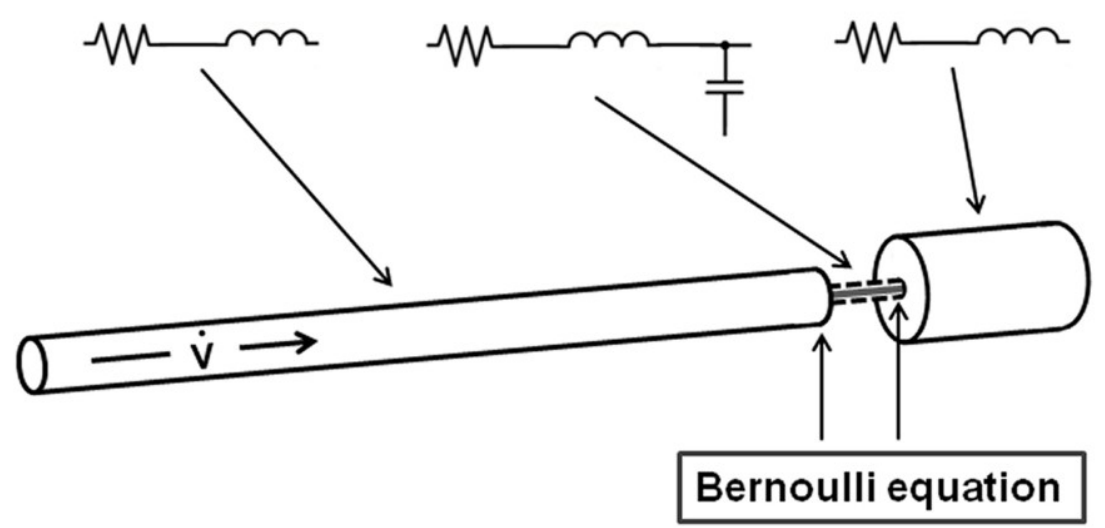

Figure A1 


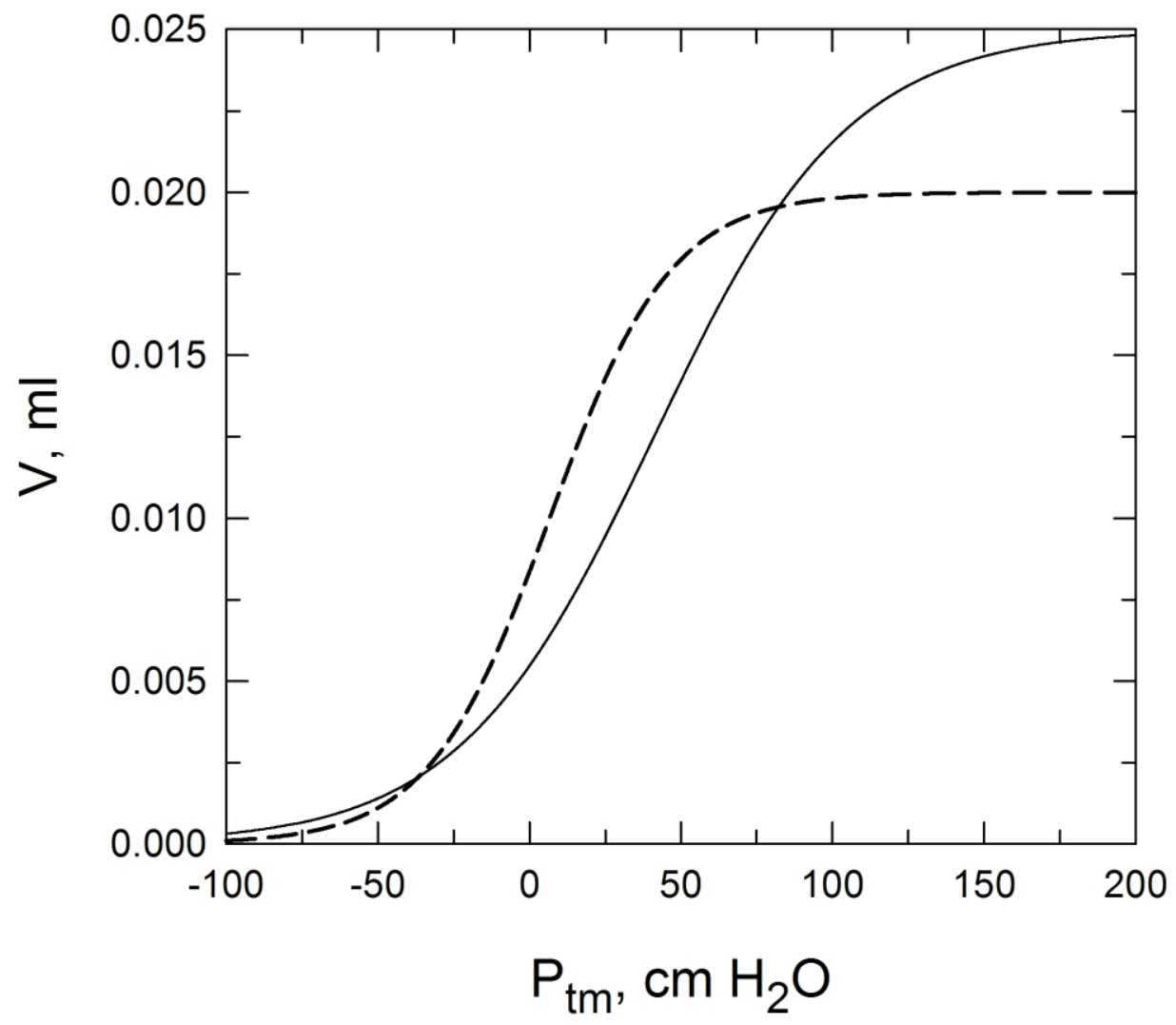

Figure A2 


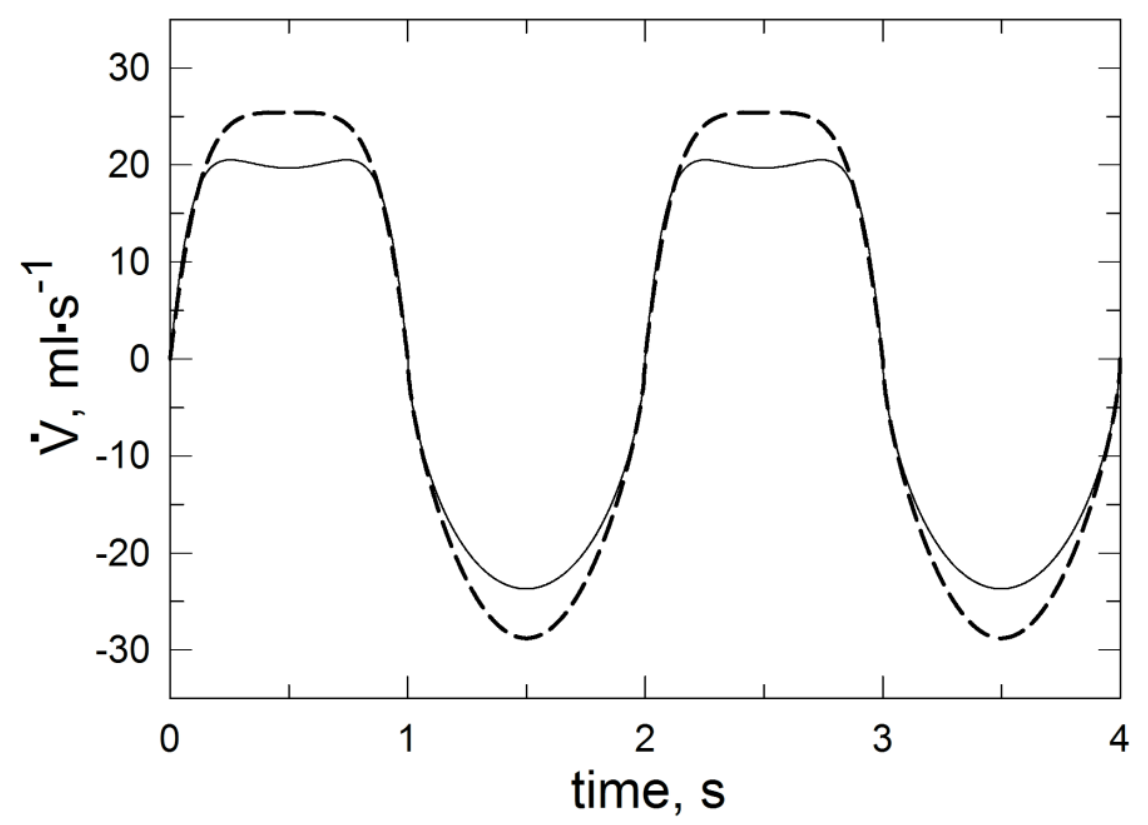

Figure A3 